\title{
Estimation of the
}

\section{Long-Run Food Price Equilibrium in \\ Germany, the U.S. and Europe}

\author{
Dissertation \\ zur Erlangung des Doktorgrades \\ der Fakultät für Agrarwissenschaften \\ der Georg-August-Universität Göttingen
}

\author{
vorgelegt von \\ Stefan Meyer \\ geboren in Nördlingen
}

Göttingen, November 2012 
1. Referent:

2. Korreferent:

Tag der mündlichen Prüfung:
Jun.-Prof. Xiaohua Yu, PhD

Prof. Dr. Bernhard Brümmer

15. November 2012 
Oh yes, dig him sweet; now there's thoughts in that mind that I would give my last arm to know; to climb in there and find out just what he's poor-ass pondering about this year's turnip greens and ham.

Jack Kerouac 


\section{Acknowledgements}

This PhD-Thesis comprises the results of my research at the Courant Research Centre Poverty, Equity and Growth of the Georg-August-Universität Göttingen. Its creation was a very educational and interesting process for me. With the following words, I want to briefly express my gratefulness to the people, who supported me the most during that time.

At first, I have to mention my advisor Jun.-Prof. Xiaohua $\mathrm{Yu}, \mathrm{PhD}$, who had the strongest influence on my work. He always took time for my questions and helped me with many scientific comments. Furthermore, he was very much considered to foster my economic and personal education. For instance, he promoted my research trips to China as well as to Penn State University, or he encouraged me to participate in various international conferences.

Next, I want to thank Prof. Dr. Bernhard Brümmer and Prof. Dr. Thomas Kneib, who were the other members of my examination board. Their comments and requests were very helpful for the finalization of the thesis.

During my time at Penn State University, I was very much supported by Prof. David Abler, $\mathrm{PhD}$. I want to thank him for the organizational help and that he inspired me by sharing his ideas.

I also have to thank my fellows at our research group, Rainer, Tian and De, for the outstanding cooperation and the good and friendly time. Beyond that, I want to mention our guests Mao and Yuan Yuan as well, who greatly joined the creative environment of our research group.

Additionally, there were many people at the Courant Research Centre, such as Friederike, Manuel, Stephan, Francisco, Chris, Andre, Sergio, Dominik and Susanne, who were important for me in various ways. 
Besides that, I have to thank my great colleagues from the development or agricultural economics groups who inspired me within conversations or discussions. Particularly, I want to distinguish Rico, Jan, Konstantin, Hannes, Sören, Kristina and Carolin.

Anyway, I could have never gone through the long process of writing this $\mathrm{PhD}$-Thesis without the presence of Dani. Thank you that you stayed "abroad" with me for such a long time.

Finally, I want to thank my family. You are the strongest backing someone can have. 


\section{Contents}

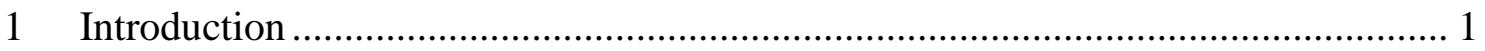

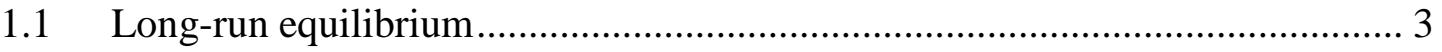

1.2 Time series properties of food prices ........................................................ 3

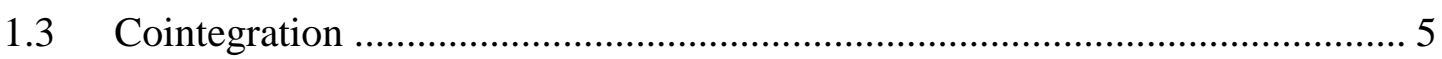

1.4 Theoretical contributions .................................................................... 7

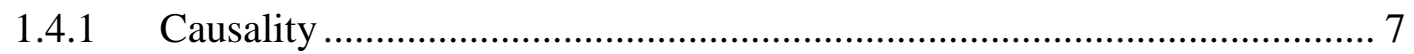

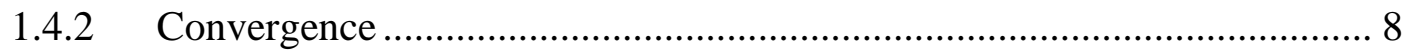

1.5 Empirical and political contributions........................................................ 11

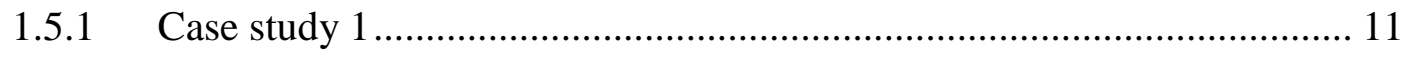

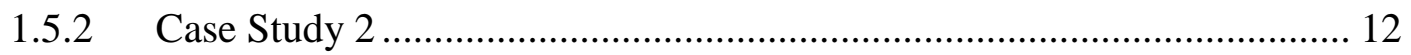

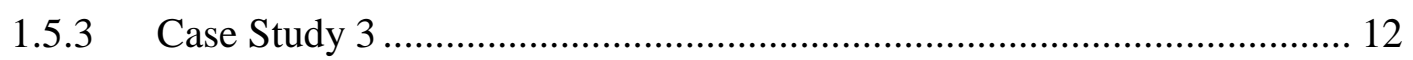

2 Long-run neutrality of money supply for food prices in Germany with policy

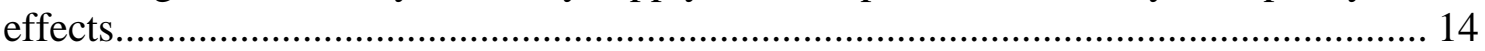

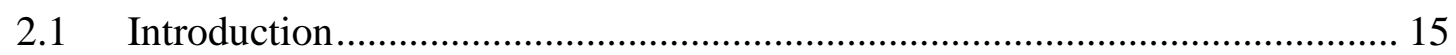

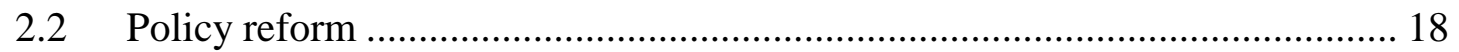

2.3 Adjusted Fisher-Seater methodology ........................................................ 20

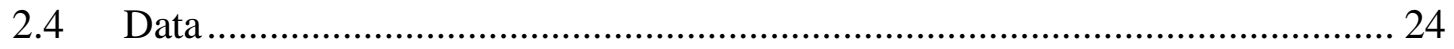

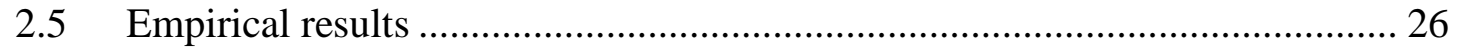

2.5.1 Aggregated agricultural price indices ............................................... 26

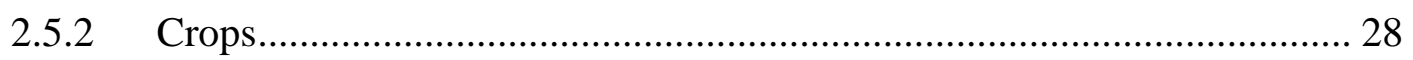

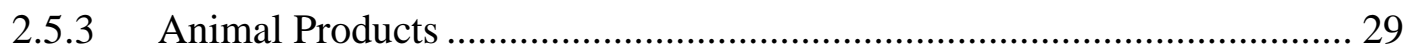

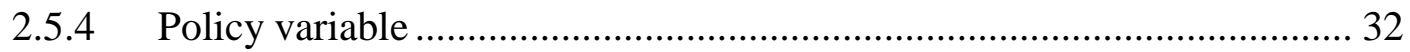

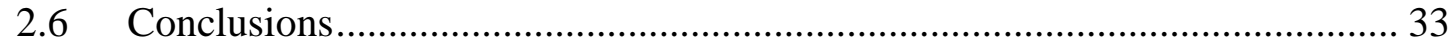

3 The long-run impact of monetary policy on agricultural prices in the U.S........... 36

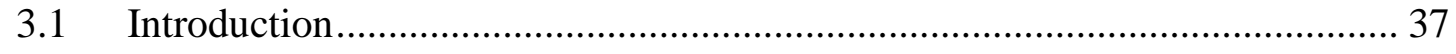

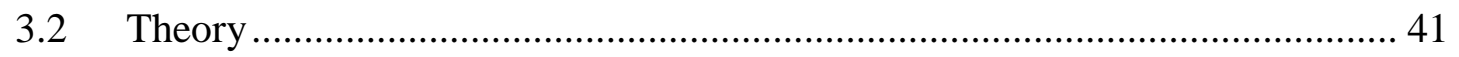

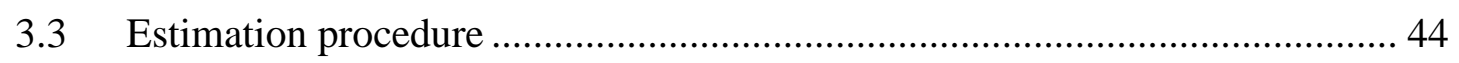

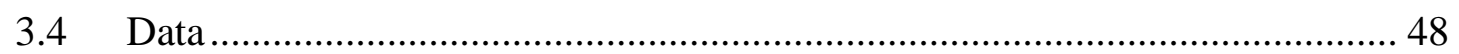

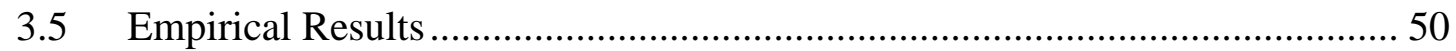

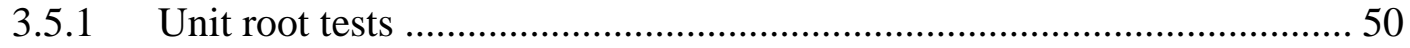

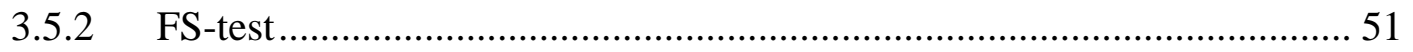

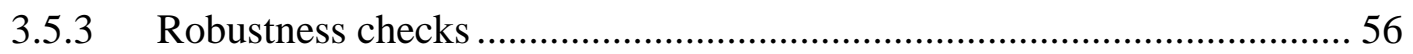

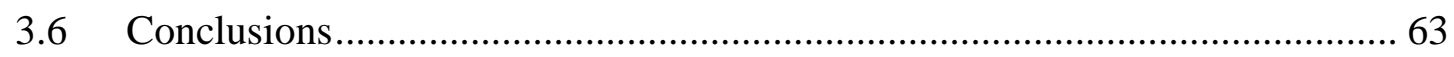

4 The Convergence of the Common Livestock Market after the Eastern Enlargement of the EU.... 


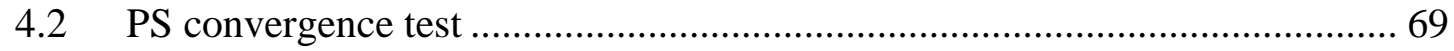

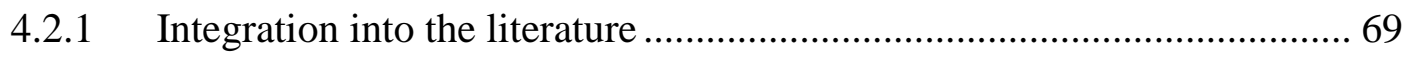

4.2.2 Convergence within a time-varying factor model .............................. 70

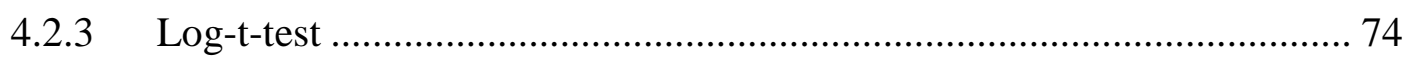

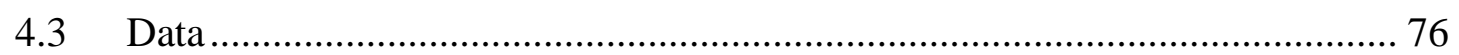

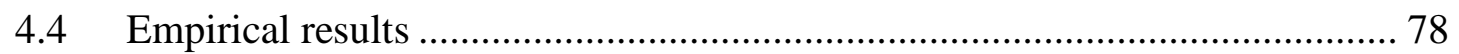

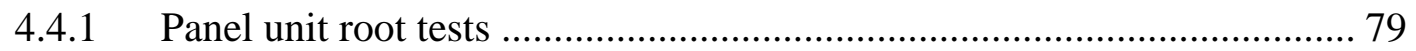

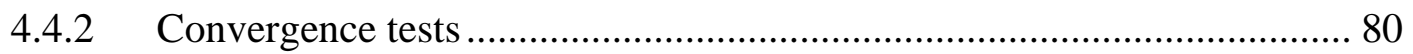

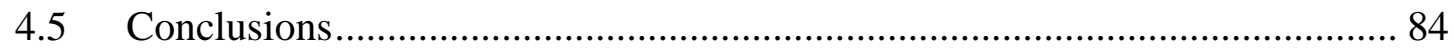

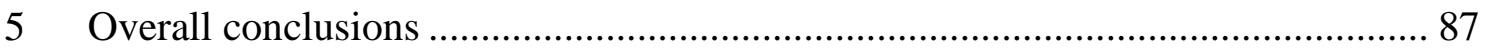

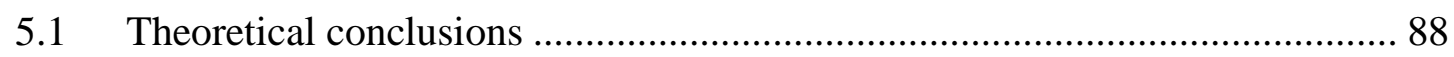

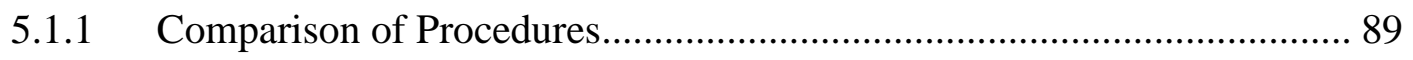

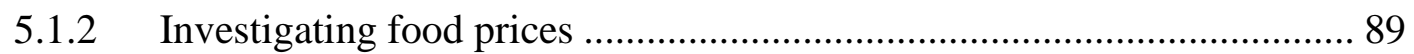

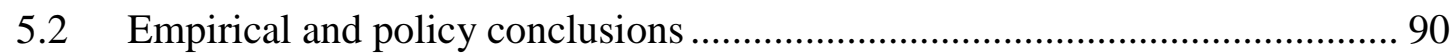

5.2.1 Long-run impact of money supply on food prices ................................ 90

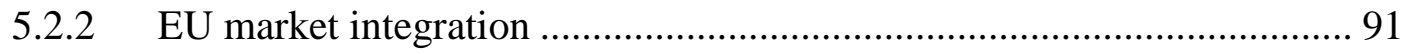

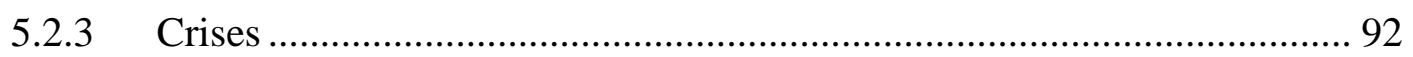

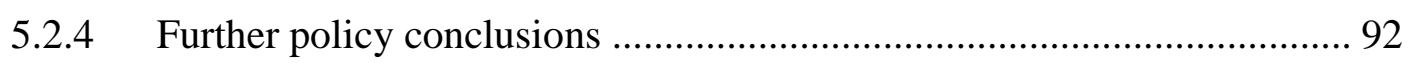

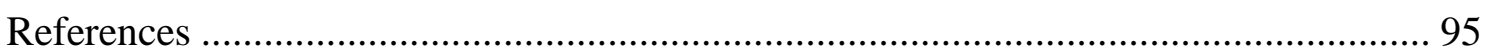

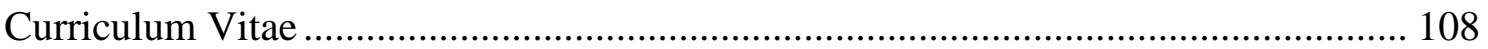




\section{Figures}

Figure 2.1: Real money supply and aggregated agricultural price indices (January 2002 until November 2012)

Figure 2.2: Long-run impact of real money supply on food prices (API, crops and animal products)

Figure 2.3: Long-run impact of real money supply on food prices (cereals, wheat, fruits

$\&$ vegetables)

Figure 2.4: Long-run impact of real money supply on food prices (livestock, cattle and hogs) 30

Figure 2.5: Long-run impact of real money supply on food prices (milk, poultry and eggs)

Figure 3.1: U.S. real money supply and PPI between November 1960 and February 2011

Figure 3.2: Long-run impact of real money supply on aggregated food prices

Figure 3.3: Long-run impact of real money supply on disaggregated food prices

(livestock, milk, grain and fruit)

Figure 3.4: Long-run impact of real money supply on disaggregated food prices (poultry, eggs and vegetables)

Figure 3.5: Long-run impact of real money supply on aggregated food prices before 2007

Figure 3.6: Long-run impact of real money supply on disaggregated food prices

(livestock, milk, grain and fruit) before 2007

Figure 3.7: Long-run impact of real money supply on disaggregated food prices (poultry, eggs and vegetables) before 2007

Figure 3.8: Long-run impact of real money supply (M3) on aggregated food prices .... 60 Figure 3.9: Long-run impact of real money supply (M3) on disaggregated food prices (livestock, milk, grain and fruit).

Figure 3.10: Long-run impact of real money supply (M3) on disaggregated food prices (poultry, eggs and vegetables)

Figure 4.1: Mean $h_{i, t}$ series of different subsamples of the price panels 83

Figure 4.2: Standardized food consumption expenditure of households in three member states of the EMU, which were affected by the euro crisis (Source: OECD.Stat) 84 


\section{Tables}

Table 2.1: ADF test for unit roots in both the real money supply series and the different

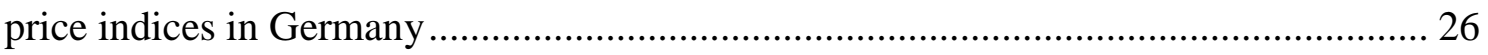

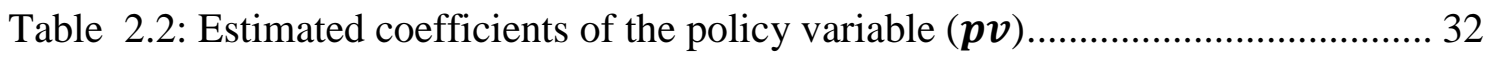

Table 3.1: Results of a unit root and a stationarity test ............................................ 51

Table 4.1: Descriptive statistics of the pork prices and further exogenous facts of the countries

Table 4.2: Descriptive statistics of the beef prices and further exogenous facts of the countries 78

Table 4.3: Results of several panel unit root tests for the beef and pork prices ............ 79

Table 4.4: Log-t-test for the livestock price panels of the EU member states .............. 80

Table 4.5: The results of log-t-tests on subsamples of the price panels ........................ 81 


\section{Summary}

In this thesis, so far insufficiently considered characteristics of long-run equilibriums in food markets are investigated. For this purpose, multivariate time series methodologies, which were developed for the estimation of long-run relationships by allowing for causality and convergence, are employed. In three essays, the proposed procedures are applied to food prices in Germany, the United States and Europe.

The long-run equilibrium is defined as a state of an economic system (e.g. a market), to which the variables of the system revert as a consequence of economic mechanisms after being affected by shocks. For the analysis of a long-run equilibrium scholars usually resort to the framework of cointegration. However, the corresponding econometric tests are limited to detecting the existence of a fixed long-run equilibrium of endogenous variables. This thesis contributes to the literature by proposing alternative methodologies, which enable an estimation of long-run equilibriums and thereby allow to take further properties into account, such as causality and convergence.

Exogenous shocks, like macroeconomic or policy changes, evidentially have an influence on food markets. Analyses of such relationships benefit from the procedures, which actually consider the causality structure. A well-known methodology, which measures the impact of a permanent change in the level of one variable on the level of another variable, is the long-run neutrality test of Fisher and Seater (1993). Their procedure is utilized here to investigate the influence of exogenous shocks on food prices. This empirical application is the first undertaking of this kind to be used in the literature. Furthermore, an extension of the basic framework is proposed, which considers a second exogenous variable in the relationship. 
However, in some markets the long-run equilibrium is not fixed. The alterations might be triggered by policy measures or changes in market characteristics (e.g. spatial modifications, transaction cost reductions or supply chain improvements). The econometric concept of convergence can be deployed in order to determine whether the market efficiency is improving or worsening. In this thesis, the test of Phillips and Sul (2007), which is by definition a quite general procedure, is utilized for this purpose. The concept of convergence, particularly the aforementioned test, has not yet been employed intensively to study the dynamics of food markets.

Furthermore, this thesis makes important empirical and political contributions to the analysis of food markets. In the first case study, the impacts of money supply changes initiated by the European Central Bank and of agricultural policy modifications implemented by the European Commission on German food prices are investigated. Research into the influence of money supply on agricultural product prices has never been conducted on such a disaggregated level before. The results show that aggregated agricultural prices are neutral in the long run, whereas the effects differ for different disaggregated markets. Staple food prices in particular, are more sensitive to changes in money supply due to good storability and demand inelasticity. In contrast, animal product prices are less sensitive to money supply changes, perhaps due to larger demand elasticities and quick production adjustments. Furthermore, the policy component in the model reveals that the dynamics triggered by the EU's decoupling policies (Mid-Term Review) increase production efficiency for specific products.

In a second case study, a theoretical model, which explains the influence of money supply on food markets, is derived in order to research the long-run impact of money supply on U.S. agricultural prices over the last five decades. The results reveal that agricultural prices as a whole and most individual product prices are neutral in response to money supply in the long run. However, the prices of products with large 
supply elasticities with respect to money supply remain significantly below a neutral equilibrium. Hence, the producers of these commodities are particularly vulnerable to monetary policy changes.

In the third case study, the unsteadiness of the long-run equilibriums of important livestock prices within the EU is analyzed. The occasional changes in the market structure result from policy measures, which are intended to offset the remaining non-tariff trade barriers, and the enlargements of the EU. Moreover, the different currencies in the market might contribute to the heterogeneity in the adjustment to a long-run equilibrium. In order to investigate these hypotheses, the single market after the important expansion of the EU to Eastern Europe in 2004 is analyzed. Including all EU countries, the results confirm that market efficiency is increasing. In a separate analysis of the new member states, their catching-up process is confirmed. Additionally, a comparison of EMU and non-EMU countries shows that the common currency significantly contributes to a further integration. 
1 Introduction 
"A substantial part of economic theory generally deals with long-run equilibrium relationships generated by market forces and behavioral rules. Correspondingly, most empirical econometric studies entailing time series can be interpreted as attempts to evaluate such relationships in a dynamic framework."

Dolado et al. (2003) S. 634

Correct analyses of long-run relationships in econometrics require an exact modeling of the data generating process. To achieve this goal, it is of great importance to differentiate between different kinds of long-run relationships and to consider the factors decisive for their emergence. Specifically, this thesis considers the influences of causality and convergence on long-run equilibriums and proposes appropriate econometric methodologies for their estimation.

Especially in food markets a detailed analysis of long-run relationships is very important, as the prices of food have a direct influence on the welfare of a society. Hence, in this thesis, different long-run equilibriums of food prices are analyzed in case studies. At first, the impact of money supply on food prices in Germany and the U.S. is investigated. Thereafter, a case study on the adjustment of food prices within the EU is conducted. 


\subsection{Long-run equilibrium}

An additional implication of the quotation at the beginning is that market forces and behavioral rules are essential for the definition of economic long-run equilibriums. These mechanisms determine the relationships between the variables and restore the equilibrium state after a disturbance. According to Dolado et al. (2003, S. 635), the long-run equilibrium is "a state to which a dynamic system tends to converge over time after any of the variables in the system is perturbed by a shock". This convergence is, in a well functioning market, caused by arbitrageurs, whose actions will move prices back to their equilibrium values (Fackler and Goodwin, 2001).

In the case studies of this thesis, two examples of long-run equilibriums in food markets are analyzed. The first example is the connection between money supply and food prices. As will be outlined in Sections 2 and 3, changes in money supply, which result from decisions of the central bank, cause structural adjustments in food markets and eventually lead to a new price equilibrium. In a second example, the equilibrium between spatially separated markets is restored by the action of traders after one price in the system was hit by a shock (see Section 4).

\subsection{Time series properties of food prices}

With respect to the above definition, the long-run equilibrium is a dynamic concept. For its investigation, it is necessary to specify the properties of the time series in the system in advance. The most important long-run property is persistence, according to which time series can be divided into stationary and non-stationary 
processes. Stationary ${ }^{1}$ time series have constant first and second moments. In contrast to that non-stationary time series exhibit a time-varying mean and variance. Additionally, innovations in non-stationary processes are not transitional, which implies that they follow a stochastic trend. For most econometric procedures, which analyze the long-run equilibrium, it is necessary that time series are non-stationary.

The literature on food prices is not explicit about this property. Stigler (2011) discussed this issue intensively. The fundamental theoretical model for explaining the time series properties of storable primary commodities is the storage model, see for instance Gustafson (1958), Williams and Wright (1991) and Deaton and Laroque (1992). It explains the autocorrelation of commodity prices by exploiting the behavioral rule of agents to build up stocks if the discounted net revenues of selling in the next period are larger than the net revenues of selling in the present period. The model theoretically shows that the prices are highly autocorrelated but still stationary. Thus, the shocks to the system, which result from weather events, are not persistent. Deaton and Laroque (1992) and Peterson and Tomek (2005) confirm this result empirically, whereas the unit root tests of Williams and Wright (1991) on simulated data do not preclude non-stationarity.

In contrast to that the random-walk or efficient market hypothesis, which was developed by Fama (1965), states that food prices are non-stationary. The model concludes that, because of the efficiency of food markets, there are no arbitrage opportunities, which causes the innovations to be stochastic. However, the theory was initially developed for financial markets and is by far less relevant for food markets than the storage model (Stigler, 2011).

\footnotetext{
${ }^{1}$ In this thesis, the term stationary is used as an abbreviation for covariance stationary.
} 
Nevertheless, the empirical results are more in favor of the hypothesis of nonstationarity. Only a few authors, for instance Leon and Soto (1997) and Wang and Tomek (2007), find stationarity. They argue that the existing changes in the mean are results of structural breaks. Therefore, they utilized unit root tests, which account for structural breaks.

However, the amount of literature approving the non-stationarity hypothesis is much larger (e.g. Cuddington and Urzua, 1989; Goodwin, 1992 and Sanjuan and Gil, 2001). There are many authors, who pay attention to structural breaks as well and confirm that prices are non-stationary, see for instance Newbold et al. (2000), Newbold et al. (2005) and Ihle et al. (2011).

A general conclusion with respect to the non-stationarity of food prices cannot be drawn and scholars must rely on their specific empirical results.

\subsection{Cointegration}

For estimating the long-run equilibrium of non-stationary time series, scholars mostly rely on the concept of cointegration, which was developed by Granger (1986) and Engle and Granger (1987) (EG). Two (or more) integrated time series ${ }^{2}$ are stated to be cointegrated if a linear combination of them exists, which reduces their order of integration. The formal definition for the cointegration of two time series $x_{t}$ and $y_{t}$ is:

\footnotetext{
${ }^{2}$ The time series not only have to be non-stationary, they must furthermore have compatible long-run properties, which is equivalent to being integrated of the same degree. Integration of order $k$ or $l(k)$ means that a time series has to be differenced $\mathrm{k}$ times in order to become stationary. 


$$
x_{t}-a-b y_{t} \sim I(k-g)
$$

The cointegration relationship is abbreviated by $\mathrm{CI}(\mathrm{k}, \mathrm{g})$, and the parameters of the linear combination are called the cointegration vector $(1,-b)$.

It can be easily established that cointegrated time series follow the same stochastic trend and are therefore in a stable long-run equilibrium. For instance, two I(1) time series, e.g. food prices, are related by a $\mathrm{CI}(1,1)$. Both time series can be decomposed into an $\mathrm{I}(1)$ and an $\mathrm{I}(0)$ process $^{3}$ :

$$
\begin{aligned}
& x_{t}=\omega_{1 t}+u_{t} \\
& y_{t}=\omega_{2 t}+v_{t}
\end{aligned}
$$

where $\omega_{1 t}$ and $\omega_{2 t}$ are the stochastic trends; and $u_{t}$ and $v_{t}$ are iid with mean zero and covariance $\sigma_{u}$ and $\sigma_{v}$, respectively. The cointegration vector is (1,-b). A linear combination is only stationary if $\omega_{1 t}=\omega_{t}$ and $\omega_{2 t}=b \omega_{t}$, where $\omega_{t}$ is a common stochastic trend.

Several methods were developed to test for cointegration and to estimate the cointegration vector, see for instance EG, Johanson (1988) or Phillips and Ouliaris (1990).

\footnotetext{
${ }^{3}$ The sum of an I(1) process and an I(0) process is always an I(1) process
} 


\subsection{Theoretical contributions}

The concept of cointegration and the corresponding test procedures are only able to determine whether the time series are in a stable long-run equilibrium. This thesis contributes to the literature by proposing other frameworks, which incorporate further properties into the investigation of long-run equilibriums, such as causality and convergence. Furthermore, econometric models are proposed, which make it possible to use the additional information.

\subsubsection{Causality}

At first, the focus is placed on long-run relationships between economic variables, in which only the changes of one variable have an influence on the other variable but not vice versa. Hence, the variables in the system underlie a rigid causal structure. There are several examples with respect to food markets. For instance, exogenous changes in macroeconomic variables or policy interventions have an impact on food prices. However, the econometric tests for cointegration, which assume that all variables in the system are endogenous, do not capture this information and in turn cannot efficiently estimate the long-run relationship. ${ }^{4}$

A possible procedure, which enables an implementation of a causal relationship in the testing, is proposed by Fisher and Seater (1993) (FS). It was developed for analyzing the long-run neutrality of money. It is a hypothesis, which has puzzled macroeconomists for several decades, see for instance the pioneering works of Lucas (1980) and Geweke (1986). Long-run money neutrality is defined as an equal (no)

\footnotetext{
${ }^{4}$ The frequently used Granger Causality (Granger, 1980; Toda and Yamamoto, 1995) is not appropriate for the discussed topic because it is not able to estimate a long-run relationship.
} 
impact of exogenous changes in the level of money supply on the level of nominal (real) economic variables, such as prices.

The methodology has frequently been applied to analyze the impact of money supply on different economic variables, such as prices, income or GDP in a large number of countries, for instance by Boschen and Otrok (1994), Olekalns (1996), Serletis and Krause (1996). In addition, the test was recently applied in other fields of economics. Serletis and Gogas (2004) and Wallace and Shelley (2006) for instance investigated the purchasing power parity, whereas Chen and Chou (2010) analyzed the impact of exchange rates on economic variables.

The FS test is described in more detail in Sections 2 and 3. Additionally, in Section 2, the basic bivariate model is enlarged by additional exogenous variables. The new specification enables the testing of the impact of two exogenous variables on one endogenous variable.

\subsubsection{Convergence}

A second important property of long-run equilibriums is that they do not have to be stable. The relationships of the variables might be in a process of narrowing or widening as a result of exogenous changes. For instance, in spatially separated food markets such developments could mean that the integration is improving or worsening because the markets might be influenced by policy measures or changes in the market structure (e.g. spatial modifications or technological progress). Therefore, a test for a stable long-run equilibrium, like a cointegration test, is not appropriate. A possible econometric concept, which correctly incorporates such a situation, is the so-called convergence, which is rarely used for market analysis. 
Nevertheless, there is a large amount of literature on convergence in other economic fields. It was initially developed for growth models. In this context, two discrete concepts were defined. The first one is beta-convergence, which means that countries which were initially poorer have larger average growth rates in the future (Barro and Sala-i-Martin, 1992). The second one is sigma-convergence, which describes a decrease of the cross-country distribution of income between a starting period and a future period (Barro and Sala-i-Martin, 1995).

The concepts were adjusted to time series analysis and other topics. Bernard and Durlauf (1995) defined convergence for economic variables $(y)$ of two (or more) units $i$ and $j$ :

$$
\lim _{k \rightarrow \infty} E\left(y_{i, t+k}-y_{j, t+k} \mid I_{t}\right)=0
$$

where $I_{t}$ represents all information available at time $t$.

In order to analyze convergence using time series approaches, scholars mainly focused on beta-convergence. This was usually done by applying unit $\operatorname{root}^{5}$ and cointegration tests, see for instance Quah (1990), Bernard (1991), Bernard and Durlauf (1992). However, criticizing the rigid structure of the approach, several authors developed more flexible convergence tests. ${ }^{6}$

Convergence among a large number of time series is frequently analyzed using panel estimation methodologies. In such cases, panel unit root tests were utilized for

\footnotetext{
${ }^{5}$ The unit root was tested for the distance between a variable and either a benchmark variable or the mean of the variables.

${ }^{6}$ Hall, Robertson and Wickens (1997), St. Aubyn(1999) and Datta (2003) used time-varying frameworks based on the Kalman Filter. Other authors developed semi-parametric tests. A first attempt was done by Nahar and Inder (1998), which was further developed by Bentzen (2005).
} 
analyzing beta-convergence. There are several examples in the economic literature, see for instance Evans (1998), Pedroni and Yao (2006) or Carrion-i-Silvestre and GermanSoto (2009). However, panel datasets were also regularly investigated with respect to sigma-convergence. This is usually done by testing for the trend parameter of disturbance indices of the cross-section of the panel. Examples of applications in different economic fields include Proietti (2005), Young et al. (2007) and Fousekis (2008).

In this thesis, the panel convergence test of Phillips and Sul (2007) (PS) is applied, which was developed based on a time-varying factor model. This methodology is quite different from the procedures summarized above. Nevertheless, the PS test envelopes the discussed concepts. It encompasses the estimation of sigma- and betaconvergence (i.e. of catching-up processes, see Section 4). Furthermore, as opposed to cointegration tests, it enables the estimation of the equilibrium dynamics. Additionally, it does not persist on a common adjustment path for the time series; and for the standard test a prior distinguishing between convergence to a non-stationary or a trend stationary common trend is not necessary. In Section 4, we additionally propose a modification of the PS methodology for testing convergence of stationary panels, which is specifically important for food prices, see the discussion in Section 1.2.

The PS test is described in more detail in Section 4. The concept of convergence was not yet applied intensively to the investigation of food markets and the PS test was never applied to food prices before. 


\subsection{Empirical and political contributions}

This thesis makes important empirical and political contributions to the analysis of food prices. In separate case studies, we investigate several issues related to long-run relationships within food markets.

\subsubsection{Case study 1}

In this case study, the impact of money supply changes induced by the European Central Bank (ECB) and the impact of the Mid-Term Review (CAP) on aggregated and disaggregated food prices in Germany are analyzed.

This empirical investigation is particularly important due to the expansionary monetary policies following the recent financial and economic crises. The analysis of the impact of money supply on food prices makes it possible to draw policy conclusions, which could be implemented to prevent negative outcomes, such as food price spikes.

Moreover, the case study investigates specific aspects of this topic, which had not yet been analyzed in the referenced literature. This is specifically true for the longrun impact of money supply, even though knowledge about its long-run consequences would help to avert adverse developments in agricultural markets. Furthermore, investigations of individual agricultural sectors have not yet been conducted. In this case study additional information on long-run consequences and specific markets are used to formulate concrete policy advice. In addition, the impact of the euro money supply was never analyzed for a specific member state.

Besides that, the Mid-Term Review was an important adjustment of the CAP. With this policy reform all remaining payments, which were coupled to the agricultural 
production, were abolished. Therefore, this process had a strong impact on the different agricultural sectors, which can be explained by comparing the results.

\subsubsection{Case Study 2}

The subject of the second case study is the investigation of the long-run impact of money supply on US agricultural markets.

An analysis of the recent quantitative easing policies can again be used to draw important policy conclusions, which would enable policy makers to derive strategies that could reduce negative consequences. Moreover, because the U.S. is the largest exporter of agricultural commodities in the world, this advice is not only relevant for domestic policy makers but for policy makers worldwide.

The case study also contributes to the literature by theoretically explaining the impact of money supply on food prices. For that purpose, a simple model based on the structural equations of agricultural markets including the money supply is derived. The results explain the impact of money supply on food prices dependent on the demand and supply elasticities of the corresponding commodities. To validate the theory, the theoretical and the empirical results can be compared.

\subsubsection{Case Study 3}

In the third case study, the unstable long-run equilibriums of the EU beef and pork markets after the important EU enlargement to Eastern Europe in 2004 are analyzed. 
There are several causes for the changing price equilibriums in EU markets. For instance, the EC implemented the Food Price Monitoring Tool, which is supposed to increase the price homogeneity within the EU food markets. Additionally, the enlargement of the EU by ten Eastern European and Mediterranean countries changed the market structure. The market integration might increase due to the abolition of nontariff trade barriers. In contrast to that, the different currencies in the EU markets could increase price heterogeneity. Especially, due to the euro crisis, there might have been some severe disturbances. Furthermore, these causes for a changing relationship might have different influences on the different livestock markets. There could be individual adjustment paths to price homogeneity because of prior gaps in integration, which are quite severe with respect to pork and beef markets due to agricultural policies and production structures.

As there is not much literature on the factors, which contribute to the convergence of the prices within a market, this case study delivers pioneering insights. Furthermore, based on the potential for further improvements of market efficiency, sensible policy advice can be derived. 


\section{Long-run neutrality of money supply for food prices in Germany with policy effects ${ }^{7}$}

${ }^{7}$ This case study was jointly written with Xiaohua Yu and presented at the EAAE Congress 2011 in Zürich. 


\subsection{Introduction}

Since FS developed an approach to testing the long-run neutrality of money supply on other economic variables in an ARIMA framework, the approach has been extended and widely applied in a number of contexts, such as price changes. Bullard (1999) conducted a comprehensive review of the literature in this field. Prices are a key issue in the agricultural policy arena, as food prices are strongly linked to both producers' and consumers' welfare. The strength of this link has given rise to a large number of academic studies in which price analyses in agricultural markets has been conducted, particularly for price transmission between different products or across different regions. Meyer and von Cramon-Taubadel (2004) have provided a very thorough review of the literature in this particular strand. However, macroeconomic variables such as monetary supply are also known to have an impact upon the prices of agricultural products (Barnett et al., 1983). By adopting FS's approach, we will shed light on the long-run impact of money supply on agricultural prices.

The period after the 2008 financial crisis is a good area of great interest, because policy makers have generally made expansionary monetary policies in order to stimulate weak economies, which could greatly benefit from the results of such research. For instance, the ECB started to reduce the liquidity shortage of banks on a large scale in August 2007, which has led to a tremendous increase in money supply. Figure 2.1 shows the development of the money supply in Germany, where M2 in terms of its share has increased by more than $10 \%$ in 2009 and 2010. Following this, agricultural commodity prices have been heavily disturbed, which resulted in substantial impacts on the welfare of both consumers and producers. It is thus important for policy makers to identify the impact of money supply shocks, so that they can take the necessary measures to protect both farmers and consumers. 


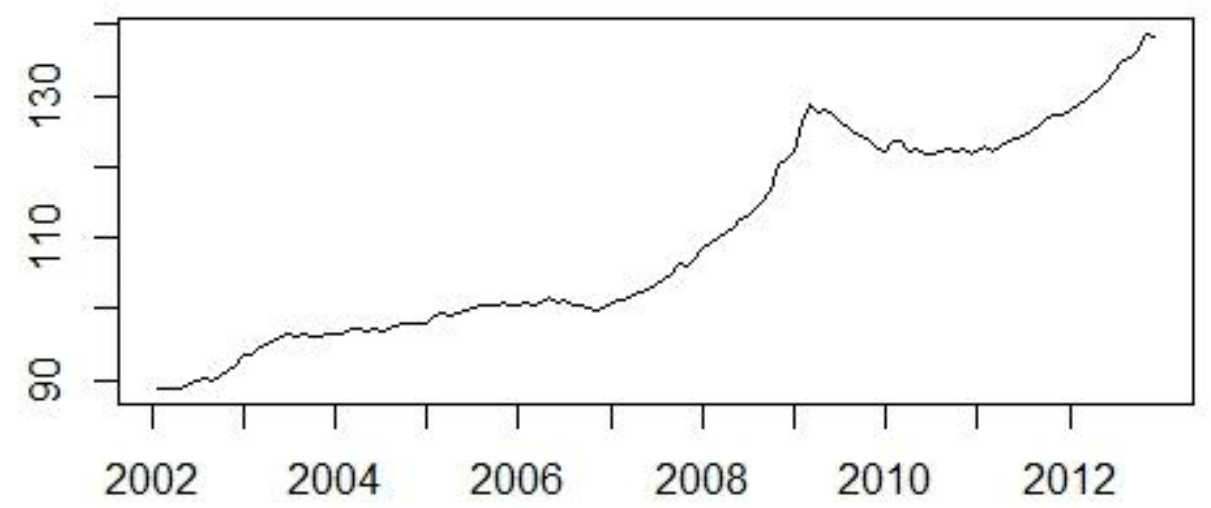

a) Index of real money supply

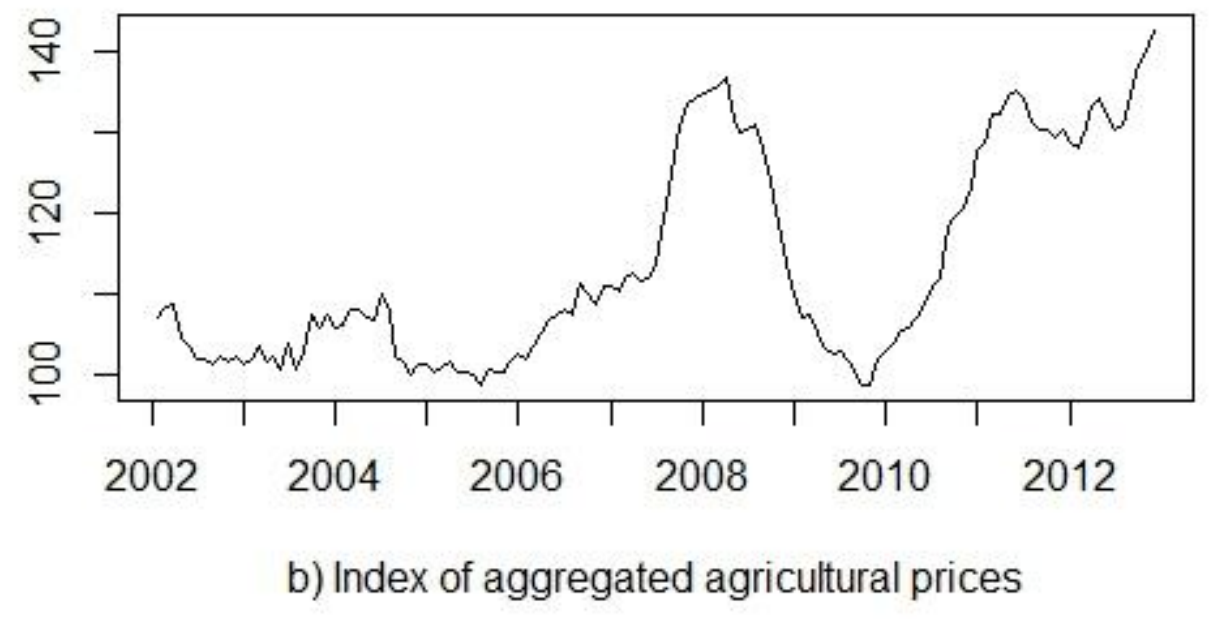

Figure 2.1: Real money supply and aggregated agricultural price indices (January 2002 until November 2012)

Agricultural prices are influenced by many factors. Hence, the responses of agricultural prices to money supply shocks are not easily predictable, as changes in money supply have different effects on producers and consumers respectively through different channels. If food prices are inelastic, an increase in money supply could push up food prices dramatically in the short run due to demand effects or speculation. For 
instance, the world food crisis in 2007 and 2008, caused by high food prices, was possibly triggered by the over-supply of money (Torero and von Braun, 2008). On the other hand, an over-supply of money could pump a lot of liquidity into production, which would eventually increase the supply in the long run and possibly reduce the prices. The aggregate effect of money supply on food prices is hence ambiguous in the long run and might be dissimilar for different products.

Agricultural prices in European countries are very dynamic, particularly in times of integration and policy reform. The formation of the Eurozone makes the impact of the monetary supply heterogeneous within each member country due to economic imbalances. For instance, the supply of money by the ECB may have different impacts on wheat prices in France and Germany respectively due to different resource endowments and economic structures. Thus, in order to estimate the dynamic effects of money supply on food prices, we should look at each country separately.

In addition, European countries are experiencing a transition of agricultural policies from coupled price policies to decoupled price policies, and the breaking point was the Mid-Term Review in 2003. Because policy reforms usually have a range of effects on production, their impacts on prices are complicated and also hard to predict. Nevertheless, we should consider policy effects when analyzing the dynamic impact of money supply on food prices.

The literature assessing the impact of monetary changes on agriculture has a long tradition. During the 1980s, extensive research revealed the impact of expansionary monetary policy in the 1970s. In his seminal paper, Schuh (1974) evidenced the impact of monetary variables on agricultural commodity prices. Traditionally, mainstream literature on the topic has dealt with the short-run influence of monetary policy on the income of farmers in the US. Examples include Tweeten 
(1980), Chambers and Just (1982), Chambers (1984) and Orden (1986). Analyses of monetary impacts on farmers in European countries have been conducted only in a very limited way. One of these rare studies is that of Kaabia and Gil (2000), who analyzed the co-integration relationship of monetary and agricultural variables in Spain between 1978 and 1995 and found long-run equilibrium for aggregated agricultural output and input prices, but the specific mechanism is still unclear.

To empirically study the long-run impact of the real money supply and policy reforms on food prices in the EU, we conduct a modified long-run neutrality test akin to that which was originally developed by FS. For this purpose we use a German monthly time series dataset, which runs from January 2002 until November 2012.

The rest of this case study is structured as follows: Section 2.2 summarizes the Mid-Term Review; Section 2.3 introduces the modified FS approach with consideration of policy effects, which is followed by a description of the data in Section 2.4; the empirical results are discussed in Section 2.5, and finally in Section 2.6 conclusions are drawn and policy implications are made.

\subsection{Policy reform}

Besides the exogenous impact of real money supply, we also shed light on the long-run policy effects resulting from the Mid-Term Review on distinct agricultural markets. The reform finally abolished all payments, which were directly coupled to the production of a specific commodity in order to increase the market orientation and competitiveness of farmers. The implementation of the reform in the member states was 
quite heterogeneous, because each country was free to choose the nature of transformation.

In Germany, the government adopted an immediate decoupling in 2005 by implementing the so-called "hybrid-model". This means, that the average coupled payments, which were paid between 2000 and 2002, were distributed as transitory disbursements according to acreage. These payments were divided into arable land, grassland and single farm premiums. The former was a transformation of the amount paid as premiums for "Grande Cultures", which was coupled to the production of cereals, oilseeds and protein plants. In the reform, the eligibility of the disbursements was enlarged to cover all other crops as well as set-aside areas. The total amount of the grassland premium, which since 2005 has been paid to farmers for each hectare of permanent grassland, consists of the sum of two former payments: the first is the slaughter premium for cattle and the other is half of the extensification premium. The single farm payment preserved the farm-specific amount of coupled disbursements and is paid to those farmers who received the original payments. For instance, cattle growers receive the remaining $50 \%$ of the extensification premium, the suckler cow premium and the special beef premium, and dairy farmers are eligible to get single farm payments, resulting from the former milk premium. Between 2007 and 2013, those transitory disbursements converge year by year into a pure regional payment scheme with fixed payments for each hectare in a region.

Additionally, the single farm payment is reduced in yearly steps, which is called the modulation. The absorbed amount of money is transferred into payments for rural development. $^{8}$

\footnotetext{
${ }^{8}$ BMELV (2005) and BMELV (2006) provide detailed information about the Mid-Term Review and its implication in Germany.
} 
The decoupling process implemented by the Mid-Term Review can cause several long-run impacts on agricultural markets, including food prices, as the policy tried to reduce market distortions and increase market functions as well. For instance, Sckokai and Moro (2009) and Serra et al. (2009) show that decoupling policy reforms can have a persistent impact on the markets, due to farmers adjusting their production and investment. Besides that, the stronger market orientation of the farmers within the different EU countries can cause a specialization of production according to comparative advantages. These progresses might lead to a demand increase for certain German goods, which would ultimately raise prices, and could also lead to rising imports of more efficiently produced goods from other member states, which would decrease the prices.

Consequently, the Mid-Term Review influenced agricultural prices in various ways, and considering the long-run impact can generate important insights for the ongoing policy reforms of the CAP.

\subsection{Adjusted Fisher-Seater methodology}

For testing exogenous impacts, such as the excess money supply and policy changes, we need to adjust the well-known long-run neutrality test of FS. We generalize the null hypothesis by including a policy variable. In the test we will derive below, long-run neutrality for a neutrality variable with respect to an impact variable is defined as: A permanent and exogenous shock in the level of an impact variable has an equiproportionate influence on the level of a neutrality variable. Here, the main 
exogenous impact variable is money supply and the testing neutral variable is food price.

In order to identify policy effects, we also include a policy variable as an exogenous variable, which can capture the long-run effect triggered by the Mid-Term Review. For testing the dynamic policy impact, we follow OECD (2005) and use a time variable with zero before the policy change and a time trend afterwards. However, the time trend is a yearly variable, as the payments adjust year by year, and they are paid on an annual rather than monthly basis. Similarly, farmers' production decisions are also made on an annual basis.

To derive the test, we extend the bivariate ARIMA framework of FS by including a policy variable. Specifically, the main variables included in the analysis are real money supply $(x)$, food prices $(y)$ and the policy variable $(p v)$. In order to capture the impact of the world food crisis (see Figure 2.1b), we incorporate the world market prices $(z)$, as another exogenous impact variable.

The generalized system consists of three equations: ${ }^{9}$

$$
\begin{gathered}
a(L) \Delta z_{t}=u_{t} \\
b(L) \Delta x_{t}=c(L) \Delta y_{t}+v_{t} \\
d(L) \Delta y_{t}=e(L) \Delta x_{t}+f(L) \Delta z_{t}+g(L) \Delta p v_{t}+w_{t}
\end{gathered}
$$

\footnotetext{
${ }^{9}$ In this paper, we neglect long-run super-neutrality, and disregard a deeper discussion of different specifications of the test due to the order of integration of the variables, as all prices variables in the study are I(1) processed. Further variations are explained in FS.
} 
Where $u_{t}, v_{t}$ and $w_{t}$ are independently and identically distributed with mean zero; $a(L), b(L), c(L), d(L), e(L), f(L)$ and $g(L)$ are parameters with lag operations. In order to identify the parameters, $b_{0}$ and $d_{0}$ are normalized to one. All variables of the system are in logarithms.

The long-run neutrality implies that a permanent and exogenous change in the level of real money supply captured in $\boldsymbol{v}_{\boldsymbol{t}}$ is equiproportionately influencing the level of food prices in the long run. Following FS we first define the long-run derivative (LRD):

$$
L R D_{x, y}=\lim _{k \rightarrow \infty} \frac{\partial \Delta y_{t+k} / \partial v_{t}}{\partial \Delta x_{t+k} / \partial v_{t}}
$$

LRD is undefined if there are no permanent, exogenous shocks in the neutrality variable $\left(\lim _{k \rightarrow \infty} \partial \Delta x_{t+k} / \partial v_{t}=0\right)$. Since all variables are in logarithms, equation (2.2) can also be interpreted as a long-run elasticity.

To calculate the LRD, we use the impulse-response representation of the money supply and price time series:

$$
\begin{aligned}
& x_{t}=\Delta^{-1}\left(\alpha(L) v_{t}+\beta(L) w_{t}+\gamma(L) u_{t}+\iota(L) p v_{t}\right) \\
& y_{t}=\Delta^{-1}\left(\delta(L) v_{t}+\varepsilon(L) w_{t}+\zeta(L) u_{t}+\kappa(L) p v_{t}\right)
\end{aligned}
$$

Whereas $p v_{t}$ is a deterministic variable, and the Greek letters are abbreviations for: 


$$
\begin{gathered}
\alpha(L)=\frac{d(L)}{b(L) d(L)-c(L) e(L)} \\
\beta(L)=\frac{c(L)}{b(L) d(L)-c(L) e(L)} \\
\gamma(L)=\frac{c(L) f(L)}{a(L) b(L) d(L)-a(L) c(L) e(L)} \\
\iota(L)=\frac{c(L) g(L)}{b(L) d(L)-c(L) e(L)} \\
\delta(L)=\frac{e(L)}{b(L) d(L)-c(L) e(L)} \\
\varepsilon(L)=\frac{b(L)}{b(L) d(L)-c(L) e(L)} \\
\zeta(L)=\frac{b(L) f(L)}{a(L) b(L) d(L)-a(L) c(L) e(L)} \\
\kappa(L)=\frac{b(L) g(L)}{b(L) d(L)-c(L) e(L)}
\end{gathered}
$$

In the next step, we differentiate the impulse-response representations (2.3) with respect to $v_{t}$ and define the limit for $k \rightarrow \infty$ :

$$
\begin{aligned}
& \lim _{k \rightarrow \infty} \partial x_{t+k} / \partial v_{t}=(1-L)^{-1} \alpha(L) \\
& \lim _{k \rightarrow \infty} \partial y_{t+k} / \partial v_{t}=(1-L)^{-1} \delta(L)
\end{aligned}
$$

The fraction of the equations in (2.5) is the LRD: 


$$
L R D_{x, y}=\frac{\delta(1)}{\alpha(1)}=\frac{e(1)}{d(1)}
$$

The approach to measuring long-run neutrality by FS consists of a test on the LRD, whereas the null hypothesis is one. In order to estimate $e(1) / d(1)$, FS propose the Bartlett estimator, which is the limit of the following regression's slope parameter $\theta_{k}$ :

$$
\begin{gathered}
\left(y_{t}-y_{t-k-1}\right)=\theta_{k}\left(x_{t}-x_{t-k-1}\right)+\psi_{k}\left(z_{t}-z_{t-k-1}\right) \\
+\varpi_{k}\left(p v_{t}-p v_{t-k-1}\right)+\epsilon_{k t}
\end{gathered}
$$

If the point estimates for $\theta_{k}$ are equal to or converging to one for increasing $k$, we can accept the hypothesis of long-run neutrality. There is no precise definition of "the long run". Following FS, the current literature often defines $k=30$ months as the long run (Wallace, 1999). In this case study we use $k^{\prime}$ s up to 24 , due to the shortness of the used time series. The estimated slope parameters are usually reported in graphs, which enable observation of the adjustment process as well.

\subsection{Data}

As aforementioned, the dataset covers the time period from January 2002 until November 2012, which begins at exactly the same time that Germany adopted the Euro. 
The real or excess money supply is defined as the money-supply-to-real-GDPratio. In the case study, we use the contribution of Germany to the monetary aggregate of the Euroarea. The German Federal Bank reports a monthly M2 time series, which we adjusted seasonally. The Eurostat database provides quarterly, seasonally adjusted GDP series for Germany. For the transformation to a monthly series we assume a constant growth rate over the three months.

Food prices are the monthly producer price indices published by the German Federal Bureau of Statistics (Statistisches Bundesamt). In the empirical part we conduct the test on food price indices for different levels of aggregation. At first, we run the test using an aggregated price index (API) covering all agricultural products (see Figure 2.1b) as well as a crop and an animal product price index. Then, we include disaggregated commodity groups and specific products, such as cereals, wheat, fruit $\&$ vegetables, livestock, cattle, hogs, poultry, eggs and milk in the analysis.

In model (2.1), we additionally included the world market price of food as a variable. The used time series is the monthly-published agricultural products price index of the International Monetary Fund.

In the previous section, we already mentioned that the orders of integration of the neutrality and impact variables determine the functional form of the FS procedure. In Table 2.1, we report the results of the ADF test for unit roots in both the real money supply series and the different price indices. All test results indicate that the variables are $\mathrm{I}(1)$ processed. 
Table 2.1: ADF test for unit roots in both the real money supply series and the different price indices in Germany

\begin{tabular}{lcc}
\hline & ADF \\
& Level & Lag 1 \\
\hline \hline Real Money Supply & 3.505 & $-4.739 * *$ \\
\hline API & 0.858 & $-5.175^{* *}$ \\
Crops & 0.406 & $-5.824 * *$ \\
Animal Products & 0.524 & $-6.174 * *$ \\
Cereals & 0.445 & $-6.013 * *$ \\
Wheat & 0.413 & $-6.451 * *$ \\
Fruits \& Vegetables & -0.328 & $-8.942 * *$ \\
Livestock & 1.077 & $-7.951 * *$ \\
Cattle & 1.763 & $-6.549 * *$ \\
Hogs & 0.27 & $-7.862^{* *}$ \\
Poultry & 1.588 & $-8.804 * *$ \\
Milk & -0.196 & $-5.098^{* *}$ \\
Eggs & 0.387 & $-8.062 * *$ \\
\hline \hline
\end{tabular}

Note: ** denotes significant levels at $5 \%$.

\subsection{Empirical results}

Figures 2.2 and 2.3 depict the changes of the influence of real money supply shocks on aggregated and disaggregated food prices by the utilization of modified FS methodology. The lag length $k$ is up to 24 and the estimated slope parameters of equation (2.7) are displayed on the horizontal and vertical axis, respectively. To enable significance testing we added confidence intervals, which are adjusted by the procedure of Newey and West (1987).

\subsubsection{Aggregated agricultural price indices}

Figure 2.2 reports the slope parameters of the test applying to aggregated agricultural price (API), crop and animal product prices. For the API, we observe an 
adjustment to neutrality in the long run. It implies that agricultural commodities, as a whole, are long-run neutral in response to money supply shocks.
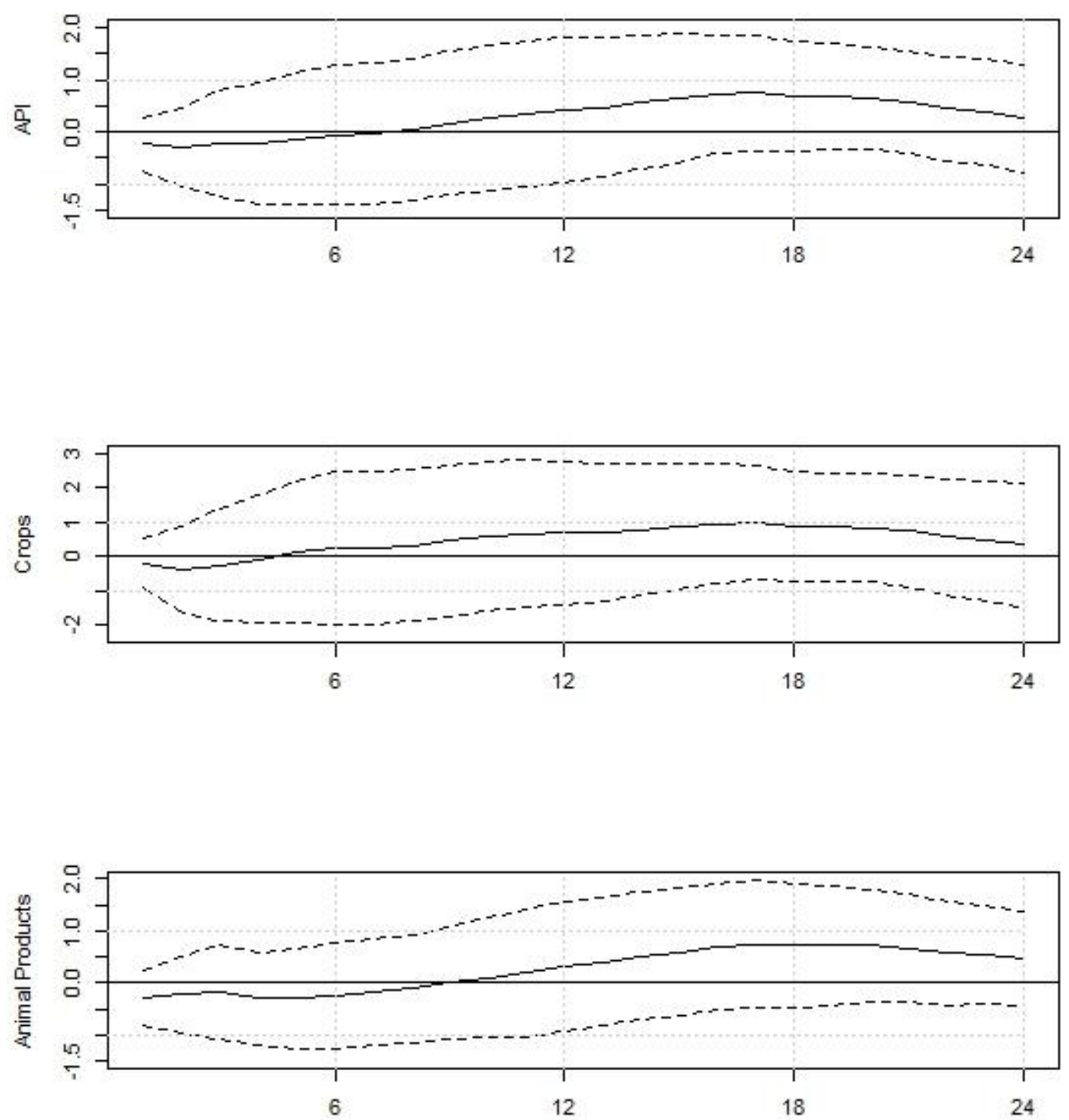

Figure 2.2: Long-run impact of real money supply on food prices (API, crops and animal products)

However, the estimated long-run coefficients for crops and animal products are different from each other. Therefore, the impact of real money supply on food prices is 
actually dissimilar for different commodities and might depend on the specific market characteristics.

To the best of our knowledge, Dorfman and Lastrapes (1996) published the only empirical study, separately disclosing the impact of money supply on disaggregated agricultural prices. Their results from an impulse-response analysis for U.S. livestock and crop markets are similar to our findings. They observe a more persistent impact on crop compared to livestock prices. However, in order to understand the differences in the adjustment processes, it might be necessary to analyze the effects in more detail for specific commodities.

\subsubsection{Crops}

The estimation results for cereals, wheat and fruits \& vegetables, are reported in Figure 2.3a. All crop prices respond very sensitively to money supply changes. It is plausible that their price elasticities are small in respect to demand (e.g. Thiele (2008) states that the price elasticities are between -0.55 and -0.83 for German staple food products). Since the money supply shock suddenly stimulates a demand due to "money illusion" or speculation and while production remains constant in the short run, the prices overshoot. The increase of the price of storable commodities, such as cereals, is particularly large in response to money supply shocks. It might be caused by declining interest rates in the capital markets and therefore ascending transfers of money into storable commodities by investors for speculation, as the expectations of inflation might drive investors to shift money into stock building (Frankel, 1986). The slightly descending prices in the long run might be a consequence of production adjustments. 

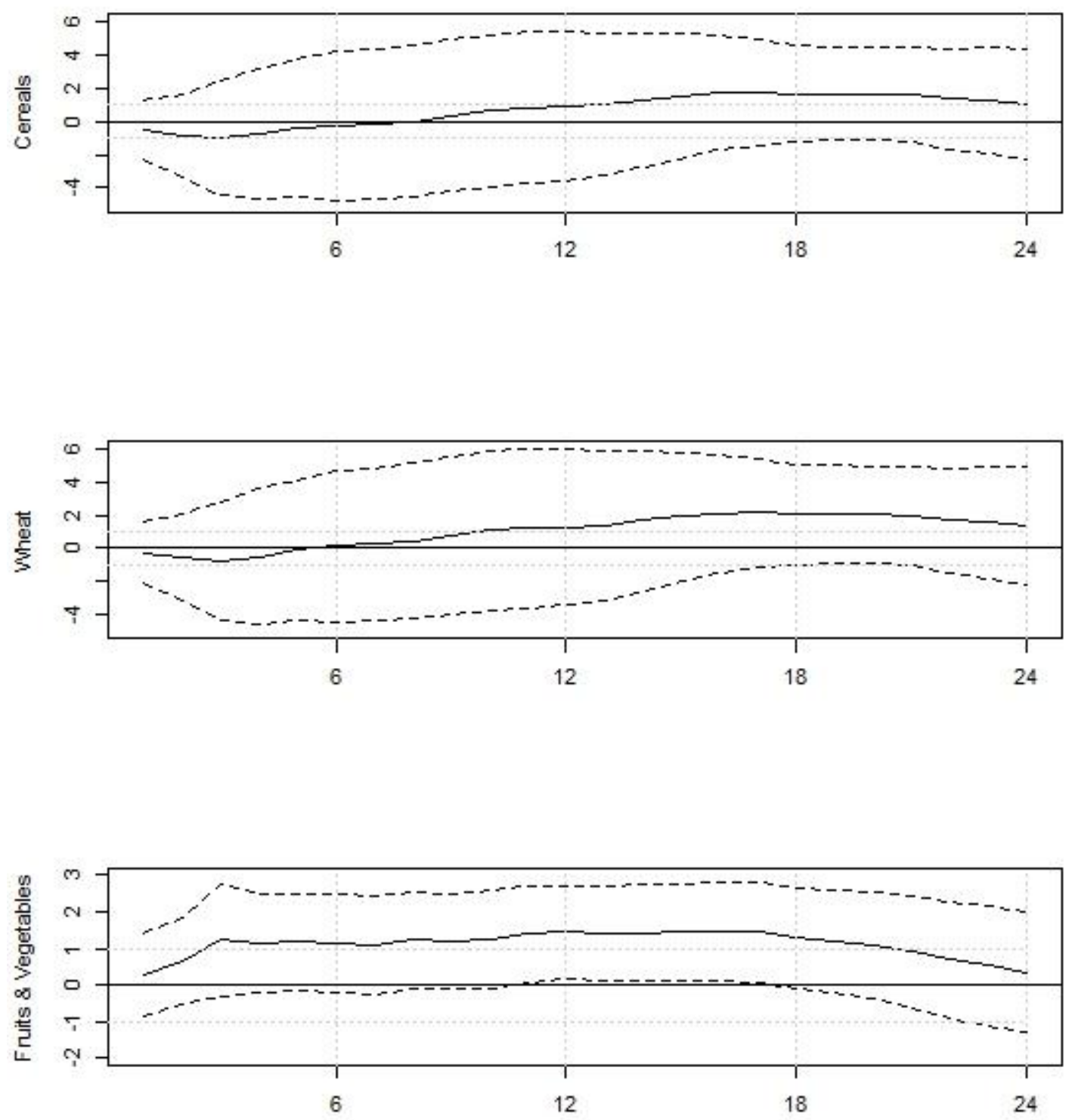

Figure 2.3: Long-run impact of real money supply on food prices (cereals, wheat, fruits \& vegetables)

\subsubsection{Animal Products}

The results for the disaggregated animal product price series are reported in Figures $2.3 \mathrm{~b}$ and $\mathrm{c}$. It emerges that the responses of livestock prices to money supply shocks are not as heavy as the responses of crop prices. This might be a consequence of 
the larger demand elasticities, for instance Thiele (2008) indicates a number of -1.02 for meat in Germany.
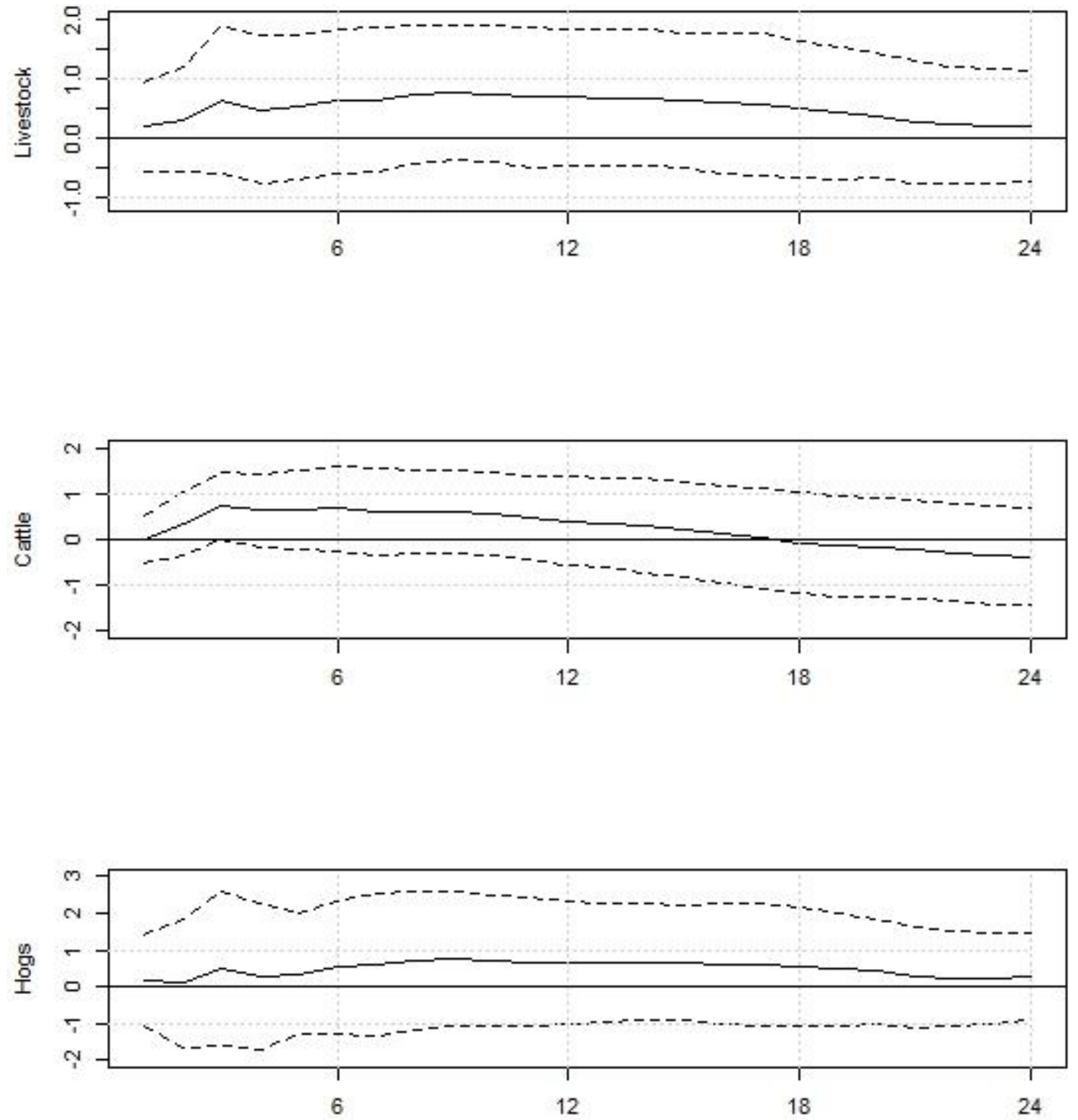

Figure 2.4: Long-run impact of real money supply on food prices (livestock, cattle and hogs)

Besides that, we disclose quicker and more severe downward movements in the cattle and hog prices, which might be a consequence of output adjustments by producers. Devadoss (1991) observed lagged supply increases after expansionary 
monetary policies, which explains the effect of passing imperfect information to farmers. Basically, such price fluctuations resulting from exogenous shocks are described by Ezekiel (1936) in the historically proved Cobweb Model. Therefore, money supply shocks might be jointly responsible for the well-known pig or cattle cycles (Hanau, 1928).
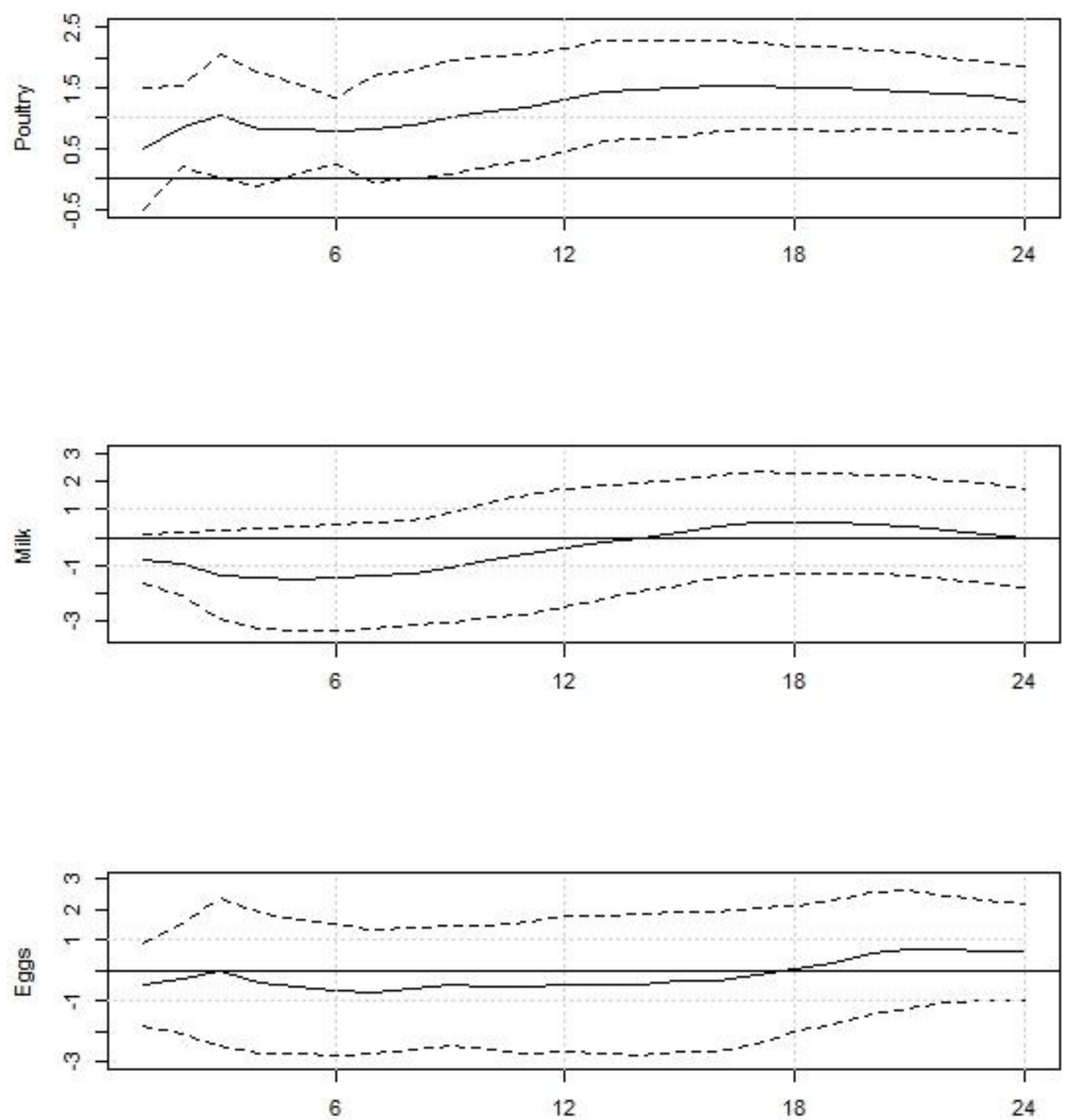

Figure 2.5: Long-run impact of real money supply on food prices (milk, poultry and eggs) 
The slowest response to expansionary monetary policies in the animal products group can be found in the milk market. This might be an aftermath of the quota system, which will be in place until 2015. The policy measures dampen adjustments due to the price of the quota and penalty payments. Consequently, it delays the prices response.

For poultry and egg prices, we find neutrality in the long run. The price setting for poultry is dominated by its most important input, which represents feeding costs. Thus, the responsiveness of cereal prices keeps the prices of poultry on a high level in the long run as well.

\subsubsection{Policy variable}

Table 2.2: Estimated coefficients of the policy variable ( $p v)$

\begin{tabular}{lcc}
\hline & $\mathrm{k}=12$ & $\mathrm{k}=24$ \\
\hline \hline API & 0.016 & 0.024 \\
Crops & 0.008 & 0.037 \\
Animal Products & 0.02 & 0.016 \\
Cereals & 0.007 & 0.041 \\
Wheat & -0.001 & 0.037 \\
Fruits \& Vegetables & 0.004 & 0.034 \\
Livestock & 0.006 & -0.012 \\
Cattle & 0.012 & -0.009 \\
Hogs & -0.001 & -0.022 \\
Poultry & 0.014 & 0.021 \\
Milk & 0.04 & 0.038 \\
Eggs & 0.089 & $0.116^{* *}$ \\
\hline \hline
\end{tabular}

Note: ** denotes significant levels at $5 \%$

Table 2.2 reports the impact of the Mid-Term Review on agricultural prices. The policy variable $(p v)$, which we included in regression (2.7) accelerates in yearly steps from 2005 on. For livestock, hogs and particularly cattle prices, we estimate negative coefficients. This result might be a consequence of the severe decoupling policies in the 
bovine sector. Therefore, the Mid-Term Review led to an improved functioning of the markets.

In contrast, all other disaggregated and aggregated price series are increasing after the policy reform. For the production of these commodities, land or cereals are major inputs. Kilian et al. (2012) showed that the land-dependent payment scheme of the Mid-Term Review could lead to rising rent and land prices. The growing production costs might be factored into the prices.

The impact of the reform on the eggs market is even significantly positive. In this sector, the effect might be strengthened by additionally tightened regularities for poultry breeders in Germany, such as the ban of battery cages (Deutsche Bundesregierung, 2007).

\subsection{Conclusions}

Even though there is a large volume of literature analyzing the impact of macroeconomic variables such as money supply on food prices, most scholars have just focused on the short-run effects. The long-run response of disaggregated food markets to the recent expansionary monetary policies is a particularly interesting area which has not yet been analyzed in much detail. Besides that, in developed countries, agricultural markets were strongly disturbed by supporting policies, and the reforms which reduced the market distortions, caused a lasting effect on agricultural prices as well. Using a modified FS model, this case study has studied the persistent impact of real money supply and agricultural policy reforms on food prices in Germany. 
Changes in real money supply result in complicated effects on producers and consumers, respectively. If food consumption is inelastic to price changes, an increase in money supply could push up food prices due to demand effects. On the other hand, over-supply of money could also pump a lot of revenue into production, which could eventually increase the supply in the long run and possibly reduce the prices again. Aggregated and in the long run, the impacts of money supply could be ambiguous.

In the empirical section, we observe that agricultural prices are sensitive to real money supply shocks. In the long run, the FS procedure indicates neutrality for the agricultural product prices as a whole. However, compared with animal product prices, we find a larger response of crop prices to money supply shocks. Analyzing further disaggregated food markets, we can confirm that staple foods in particular are strongly influenced by real money supply shocks, which perhaps results from consumer's inelasticity concerning the commodity's price changes. Furthermore, the prices of storable commodities, such as those of cereals, would soar up after the expansionary monetary policies due to money, which is additionally transferred into the markets for speculation by investors. In contrast, livestock prices are not very sensitive to money supply changes, because consumers react more elastically to shifts and the producers are able to adjust production more rapidly.

As a consequence of these real long-run effects, policy makers should pay attention to the different impacts which money supply has on different agricultural commodity markets. As the ECB just recently increased the money supply to support the banking sectors in the heavily indebted countries of the Eurozone, another spike of food prices in general and of the prices of storable grain in particular can be expected, if the relevant governments do not take the necessary measures to offset this development. 
Concerning the Mid-Term Review, we observe that the decoupling policies in the bovine sector led to decreasing prices, which confirms an improving functioning of the market and therefore a success of the reform. However, there are positive changes to the prices of most commodities. The rising land prices, as a consequence of the reform, boost the prices of most agricultural commodities. For further advancements of the CAP it is necessary that policy makers take both effects into account. 


\section{The long-run impact of monetary policy on}

agricultural prices in the U.S. ${ }^{10}$

${ }^{10}$ This case study was jointly written with Xiaohua Yu and is submitted to Agricultural Economics. 


\subsection{Introduction}

To overcome the enormous national market imbalances caused by the financial crisis of 2008, an expansionary monetary policy was implemented in the U.S., which was in its extent comparable to the policies adopted and pursued after the oil crisis in the 1970s (Orden, 2010). Given that the over-supply of money after the oil crisis has lead to severe market distortions in the agricultural sector mainly due to heavy investments and that the ensuing long-run consequences were largely contributing to the financial farm crisis in the 1980s (Barnett, 2000), it is possible that the recent expansionary money supply might again have serious consequences for this sector. However, for deriving suitable policy advice, a comprehensive understanding of the impacts of expansionary monetary policies on food prices is necessary. This is underlined in a study conducted by Gilbert (2010), who revealed the significant impact of money supply on food prices by the U.S. time series, and confirmed that financial factors might be drivers of the food crisis in 2007 and 2008.

According to the macroeconomic literature, major changes in money supply have both short and long-run impacts on commodity prices. Several models, which theoretically explain this effect, have been developed. For instance, the model of Sims (2003) explains a real short-run effect of money supply with imperfect information. In contrast to that, Golosov and Lucas (2007) argue that sticky prices are responsible for the impact, and Mackowiak and Wiederholt (2009) combine both attempts to explain the phenomena.

With respect to the long-run impact, a different picture emerges. Macroeconomists traditionally refuse a real long-run effect by referring to rational expectations (Lucas, 1972), which results in what is formally known as the neutrality of money. Real long-run effects could depend on the market structure, because an 
increasing money supply could cause both demand and supply shifts following rising incomes or exports and investments, respectively. There are two different approaches to explain the impact of money supply: The Structualist Approach and The Monetarist Approach, depending on whether money takes an active or passive role in the inflation process (Barnett et al. 1983). The structualists conjecture that the money supply is passive and the inflation originates from real shocks (Olivera, 1970); while the monetarists suggest that money supply can generate aggregate demand which can only change relative prices between commodities, but not the overall price level, so that money supply is a cause of inflation. Given the nature of the modern quantitative easing policy, monetary authorities take active roles to shock the economic system and try to correct the unbalance. To some extent, money supply hence is viewed as a causal shock rather than a passive result.

In contrast to the impact of money supply on overall price level, we are more interested in the disaggregated markets. Through the empirical analysis of the impact of monetary policies on relative prices, Lastrapes (2006) found that the real effects on disaggregated prices do persist in the long run. He argued that specific market characteristics might be important for explaining the money non-neutralities within disaggregated markets. Similarly, Bordo (1980) found that the contract length between producers and consumers is important for the transmission speed of the impact of money supply on market prices. Nonetheless, the analyses of the responses of disaggregated markets to money supply shocks might be important for an understanding of the transmission mechanism and could be used to empirically confirm the linkage between these types of macroeconomic impact and microeconomic market characteristics. 
The effects of expansionary monetary policies on agricultural prices have already been analyzed in some detail. However, most studies, such as those of Chambers and Just (1982), Barnett et al. (1983), Awokuse (2005), and Gilbert (2010) have only focused on short-run impact. The results are quite mixed, as some scholars have confirmed the existence of an impact while others have rejected it. Furthermore, several theoretical models were derived, which explain the short-run impact of money supply on food prices. The most important is the overshooting model by Frankel (1986). It is defined for an economy, which consists of two sectors: The agricultural sector with flexible prices and the manufacturing sector with sticky prices. It predicts that agricultural prices are overshooting briefly after a money supply shock occurred. Saghaian et al. (2002) extended the model and confirmed its validity empirically. Another theoretical explanation for a short-run money supply impact on agricultural prices is imperfect information. Lapp (1990) developed a corresponding theoretical model.

The impact of money supply on food prices could last for a very long time; hence it is more important to analyze the impact of money supply on food prices in the long run from a policy perspective. A considerable amount of academic literature analyzing the long-run response of agricultural prices to monetary policy, which is so far only done by applying cointegration tests, can be found in circulation. For instance, Robertson and Orden (1990), Choe and Koo (1993), Kaabia and Gil (2000) and Westerlund and Constantini (2009) have conducted cross-country analysis of its impact on aggregate agricultural prices. Their results for agricultural prices on the whole are contradicting. Some of the papers confirm and others reject the neutrality hypothesis. Furthermore, Dorfman's and Lastrape's (1996) findings are interesting in the context of our study, as they test the impact of money supply shocks on food prices, which are 
disaggregated into livestock and crop prices and discover that the impact is different for different commodities. Moreover, Section 2 found non-neutralities for several agricultural markets by analysing the responses of disaggregated food prices to money supply changes in Germany.

The response of U.S. agricultural markets to money supply changes is particularly meaningful for the world markets, because the U.S. is one of the largest agricultural producers in the world. In addition, data on agricultural commodity prices and money supply covering the last 50 years is available for the U.S.. These time series enable us to study a real long-run impact of money supply on food prices.

We first construct a theoretical framework based on the market equilibrium to look into the mechanism of the impact of money supply on commodity prices, and then adopt the approach of FS to empirically analyze the long-run impact. So far, the FS methodology has been mainly applied to various macroeconomic contexts, Bullard (1999) has carried out a comprehensive review of literature on the subject. In spite of this, the methodology has not been widely adopted in the context of food price analyses, except for a few cases such as Section 2.

The remainder of this case study is structured as follows: We derive a simple theoretical model in Section 3.2; In Section 3.3 the FS procedure is introduced and afterwards, in Section 3.4 we discuss the details of the data used for the analysis. In Sections 3.5 and 3.6, we report the empirical results and conclude by offering policy implications for producers as well as policy makers, respectively. 


\subsection{Theory}

In order to analyze the long-run impacts of money supply on agricultural prices theoretically, we utilize a model which considers money supply's effects on both supply and demand of agricultural commodities suggested by Barnett et al. (1983). Concerning the supply side, money supply can affect the investment of farmers, as they can obtain credits much more easily. This transmission of the additional money on the markets is called the credit-channel (see Gertler and Gilchrist, 1994). It can be speculated that an increase of money supply usually leads to an increase in production. Consequently, the elasticity of production with respect to money supply is often positive. On the other side, wage effects (Fischer 1977) or changes in market credit conditions can also influence the demand of agricultural commodities. For instance, falling interest rates can lead to income shifts, which can raise demand on storable commodities (Frankel, 1986) and also increase demand on tradable commodities because of depreciating exchange rates (Dornbusch, 1970; Saghaian et al., 2002).

Besides that, the changes of money supply are very complicated, and many quantitative easing tools have been developed by the central banks, such as lowering interest rates and buying government bonds. The response of food prices to money supply changes is finally determined by the extent of the credit-channel. We only use the total money supply M2 to represent market credit conditions.

We use simplified structural equations for modeling the commodity markets to derive the impact of money supply on agricultural prices. Suppose both market demand $D_{t}$ and supply $S_{t}$ are determined by money supply $m_{t}$ and nominal food price $p_{t}$, 


$$
\begin{aligned}
& D_{t}=D\left(m_{t}, p_{t}\right) \\
& S_{t}=S\left(m_{t}, p_{t}\right)
\end{aligned}
$$

Total differentiation of Equation (3.1) yields

$$
\begin{gathered}
d D_{t}=\frac{\partial D_{t}}{\partial m_{t}} d m_{t}+\frac{\partial D_{t}}{\partial p_{t}} d p_{t} \\
d S_{t}=\frac{\partial S_{t}}{\partial m_{t}} d m_{t}+\frac{\partial S_{t}}{\partial p_{t}} d p_{t}
\end{gathered}
$$

The market equilibrium condition identifies the relationship between money supply and food price change,

$$
\frac{d p_{t}}{d m_{t}}=\frac{\frac{\partial D_{t}}{\partial m_{t}}-\frac{\partial S_{t}}{\partial m_{t}}}{\frac{\partial S_{t}}{\partial p_{t}}-\frac{\partial D_{t}}{\partial p_{t}}}
$$

Rewriting Equation (3.3), gives the relationship between the money supply elasticity $(\eta)$ of food prices and demand and supply elasticities: 


$$
\eta_{p, m}=\frac{d p_{t}}{d m_{t}} \frac{m_{t}}{p_{t}}=\frac{\frac{\partial D_{t}}{\partial m_{t}} \frac{m_{t}}{D_{t} S_{t}}-\frac{\partial S_{t}}{\partial m_{t}} \frac{m_{t}}{S_{t} D_{t}}}{\frac{\partial S_{t}}{p_{t}} \frac{p_{t}}{S_{t} D_{t}}-\frac{\partial D_{t}}{p_{t}} \frac{p_{t}}{D_{t} S_{t}}}=\frac{\varepsilon_{D, m}-\varepsilon_{S, m}}{\varepsilon_{S, p}-\varepsilon_{D, p}}
$$

Where $\eta_{p, m}$ denotes the elasticity of food price with respect to money supply; $\varepsilon_{S, m}$ and $\varepsilon_{D, m}$ are respectively supply and demand elasticities with regard to money supply; and $\varepsilon_{S, p}$ and $\varepsilon_{D, p}$ are respectively supply and demand elasticities with regard to food prices.

Microeconomic theory suggests that the supply and demand elasticities with respect to food prices are often positive and negative, respectively. Consequently, the denominator of equation (3.4) is always positive. In particular, both $\varepsilon_{S, p}$ and $\varepsilon_{D, p}$ have nothing to do with money supply and $\varepsilon_{S, p}-\varepsilon_{D, p}$ can be assumed to be constant.

In contrast, both demand and supply elasticities with respect to money supply are expected to be positive as mentioned above due to their stimulating effect. Hence, the magnitude of the impact of money supply on food prices is determined by the difference between demand and supply elasticities with respect to money supply. It implies that if the supply elasticity with respect to money supply is relatively larger than its demand elasticity, $\eta_{p, m}$ could even be negative. In this case, money supply could trigger a decline in food prices due to its larger response of production. These products often have a short production cycle and standardized production procedure, and consist of articles such as chicken and certain vegetables.

On the other hand, if a demand shock dominates the response to monetary policy changes, for instance an over-proportional impact on storable or traded goods 
prices, such as the price of grain or fruit (Section 2), $\eta_{p, m}$ would be positive, but whether it is neutral $(=1)$ is unknown.

Note again that the impact of money supply could last for a very long time. Equation (3.4) implicitly assumes that all the elasticities are long-run elasticities, as the elasticities capture the overall impact of money supply. Hence, the test for long-run neutrality of money supply on food prices is exactly the test for $\eta_{p, m}=1$.

In the next section, we will derive an econometric model to empirically test if the money supply is neutral for food price $\left(\eta_{p, m}=1\right)$ in the long run. As the impact of money supply is very complicated and could last for a very long time period, the shortrun impact is not of any interest to our research.

\subsection{Estimation procedure}

In order to test $\eta_{p, m}=1$, we adopt the well-known approach developed by FS, which is applied for the analysis of the long-run neutrality for money supply in various contexts (Olekalns, 1996). Here, the term neutrality is used to describe the situation where a permanent and exogenous change in the level of real money supply has an equiproportionate impact on the level of agricultural prices (FS). The suitable test procedure relies strongly on the integration of the time series in the system.

It can be derived from a bivariate ARIMA framework describing the relationship between real money supply and food prices: 


$$
\begin{aligned}
& a(L) \Delta^{\langle m\rangle} \bar{m}_{t}=b(L) \Delta^{\langle p\rangle} \bar{p}_{t}+u_{t} \\
& c(L) \Delta^{\langle p\rangle} \bar{p}_{t}=d(L) \Delta^{\langle m\rangle} \bar{m}_{t}+v_{t}
\end{aligned}
$$

Where $\bar{m}_{t}$ and $\bar{p}_{t}$ respectively are the logarithmic forms of real money supply and nominal food prices. The characters $\langle m\rangle$ and $\langle p\rangle$ indicate the corresponding variable's order of integration. The error terms $u$ and $v$ are independently and identically distributed with mean zero, variances $\sigma_{u u}$ and $\sigma_{v v}$, respectively, and covariance $\sigma_{u v} . u$ denotes the exogenous changes in the real money supply series.

In order to conduct the test of money neutrality, FS defined the long-run derivative (LRD). It expresses a standardized long-run impact and is identical to the elasticity of food price with respect to money supply $\eta_{p, m}$ :

$$
L R D_{\Delta p, \Delta m}=\lim _{k \rightarrow \infty} \frac{\partial \Delta^{\langle p\rangle} \bar{p}_{t+k} / \partial u_{t}}{\partial \Delta^{\langle m\rangle} \bar{m}_{t+k} / \partial u_{t}}=\frac{c(1)}{d(1)}=\eta_{p, m}
$$

LRD is determined by the analyzed time series' order of integration. This dependence also affects long-run neutrality. FS specifically distinguished four cases; and they explained their specific meaning for long-run neutrality:

1. For $\langle m\rangle<1$, LRD is not defined. There are no permanent and exogenous changes in the level of money supply. Consequently, long-run neutrality is not feasible. 
2. LRD is assumed to be 0 if $\langle m\rangle \geq\langle p\rangle+1 \geq 0$. A test of long-run neutrality for nominal variables can be rejected.

3. If $\langle m\rangle=\langle p\rangle \geq 1$ is valid, LRD can be derived. Therefore, it is necessary to transform framework (3.5) into its impulse-response representations:

$$
\begin{aligned}
& \Delta^{\langle m\rangle} \bar{m}_{t}=\frac{c(L)}{a(L) c(L)-b(L) d(L)} u_{t}+\frac{b(L)}{a(L) c(L)-b(L) d(L)} v_{t}=\alpha(L) u_{t}+\beta(L) v_{t} \\
& \Delta^{\langle p\rangle} \bar{p}_{t}=\frac{d(L)}{a(L) c(L)-b(L) d(L)} u_{t}+\frac{a(L)}{a(L) c(L)-b(L) d(L)} v_{t}=\gamma(L) u_{t}+\delta(L) v_{t}
\end{aligned}
$$

By substituting equations (3.7) into (3.6), we get $\mathrm{LRD}=\mathrm{d}(1) / \mathrm{c}(1)$. Consequently, a test of LRN is possible.

4. Finally, for the cases where the relationship $\langle m\rangle=\langle p\rangle-1 \geq 1$ holds, we can specify $\mathrm{d}^{*}(1) / \mathrm{c}(1)$ for LRD. However it is only defined if $d(1)=0$. The parameter $\mathrm{d}^{*}(\mathrm{~L})$ is a abbreviation for $(1-L)^{-1} d(L)$. Again the framework enables a testing of LRN. ${ }^{11}$

Obviously, the parameters, which are necessary for calculating LRD, can be estimated in equation two of framework (3.5). Relying on the assumption that the exogenous changes in the variables are uncorrelated $\left(\sigma_{u, v}=0\right.$ ) and that the money supply is predetermined $\left(b_{0}=0\right)$ the parameters of the equation are identified.

\footnotetext{
${ }^{11}$ Similar to long-run neutrality, FS defined the existence of long-run superneutrality, which means that permanent and exogenous changes in the growth rate of money supply are equally transferred into the level of agricultural prices. For superneutrality the money supply time series has to be integrated at least of order two. However, these cases are not important in this paper as the time series do not exhibit the corresponding properties (see section 3.5.1).
} 
Furthermore, the relative parameter $\mathrm{d}(1) / \mathrm{c}(1)$ can be directly estimated in the frequency domain. Therefore, a calculation of the covariance matrix of the sequences $\left(\Delta^{\langle m\rangle} \bar{m}_{t} \quad \Delta^{\langle p\rangle} \bar{p}_{t}\right)$ is necessary:

$$
\operatorname{Cov}\left(\begin{array}{c}
\Delta^{\langle m\rangle} \bar{m}_{t} \\
\Delta^{\langle p\rangle} \bar{p}_{t}
\end{array}\right)=\left[\begin{array}{ll}
\alpha(L) & \beta(L) \\
\gamma(L) & \delta(L)
\end{array}\right]\left[\begin{array}{cc}
\sigma_{u u} & \sigma_{u v} \\
\sigma_{u v} & \sigma_{v v}
\end{array}\right]\left[\begin{array}{cc}
\alpha(L) & \gamma(L) \\
\beta(L) & \delta(L)
\end{array}\right]
$$

Additionally assuming long-run exogeneity $(b(1)=0)$, FS show that the parameter of a zero-frequency regression of the differenced prices on the differenced money supply corresponds to the $\mathrm{LRD}^{12}$ :

$$
\frac{\operatorname{Cov}\left(\Delta^{\langle m\rangle} \bar{m}_{t}, \Delta^{\langle p\rangle} \bar{p}_{t}\right)}{\operatorname{Var}\left(\Delta^{\langle m\rangle} \bar{m}_{t}\right)}=\frac{\gamma(1)}{\alpha(1)}=\frac{d(1)}{c(1)}
$$

For estimating the relative parameters, FS propose to use the limit regression of moving averages of money supply on agricultural prices, which is called the Bartlett estimator:

$$
\sum_{i=0}^{k} \Delta^{\langle p\rangle} \bar{p}_{t-i}=\mu_{k}+\theta_{k} \sum_{i=0}^{k} \Delta^{\langle m\rangle} \bar{m}_{t-i}+u_{k t}
$$

\footnotetext{
${ }^{12}$ Similarly, the relative parameter of case four $\left(d^{*}(1) / c(1)\right)$ can be estimated in a frequency-zero regression by assuming $b^{*}(1)=0$.
} 
where $\mu_{k}$ is the intercept. Equation (3.10) can be consistently estimated for the case that both money supply and agricultural prices are integrated of order one, by the following OLS regression:

$$
\left(\bar{p}_{t}-\bar{p}_{t-k-1}\right)=\alpha_{k}+\theta_{k}\left(\bar{m}_{t}-\bar{m}_{t-k-1}\right)+u_{k t}
$$

Using the test procedure, we can calculate the slope parameters $\theta_{k}$ for increasing $k$ 's. The hypothesis of long-run neutrality of the real money supply for food prices can be accepted if the LRD is either equal to or converging to one, denoting nominal commodity prices have an equiproportional increase with the increase of money supply.

\subsection{Data}

Unlike most of the existing empirical research analyzing the impact of monetary policy, we are applying real or excess money supply series in order to test the impact of the monetary policy on food prices. We use this variable, because the influence of overor under-supply of money on the markets might be persisting. This was empirically confirmed by Qayyum (2006), who shows that excess money supply has a strong impact on inflation. To measure real or excess money supply (see Figure 3.1a), we use the money-supply-to-real-GDP-ratio between November 1960 and February 2011, which consists of both the seasonally adjusted, monthly M2 (or M3) series of the U.S. Federal Reserve Bank and the seasonally adjusted, real GDP series of the U.S. Bureau 
of Economic Analysis. Since GDP is provided as a quarterly series, we transform it into a monthly series assuming constant growth rates within that quarter.

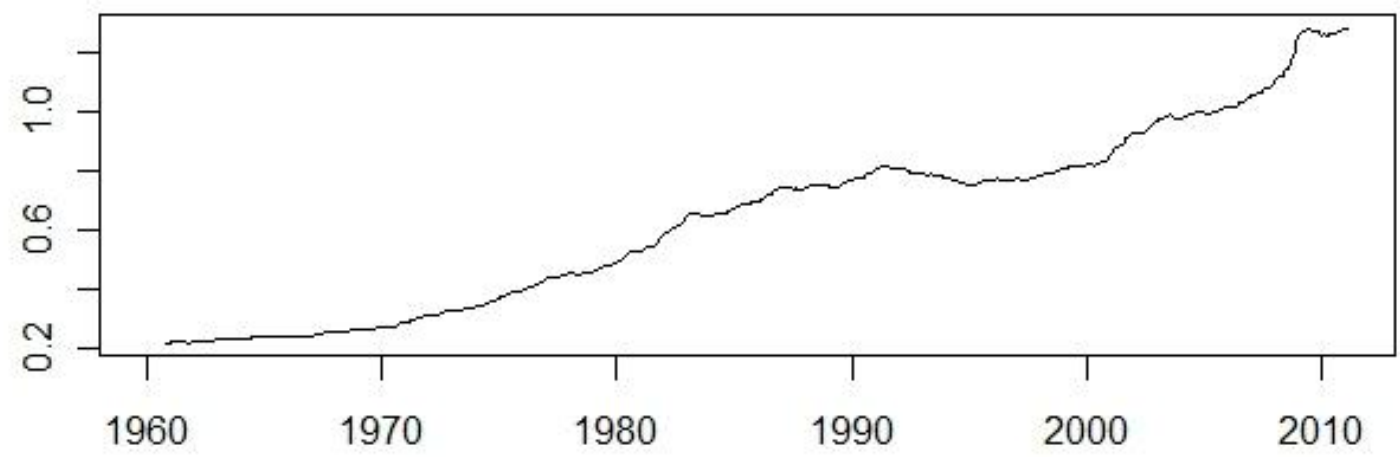

a) Index of Real Money Supply

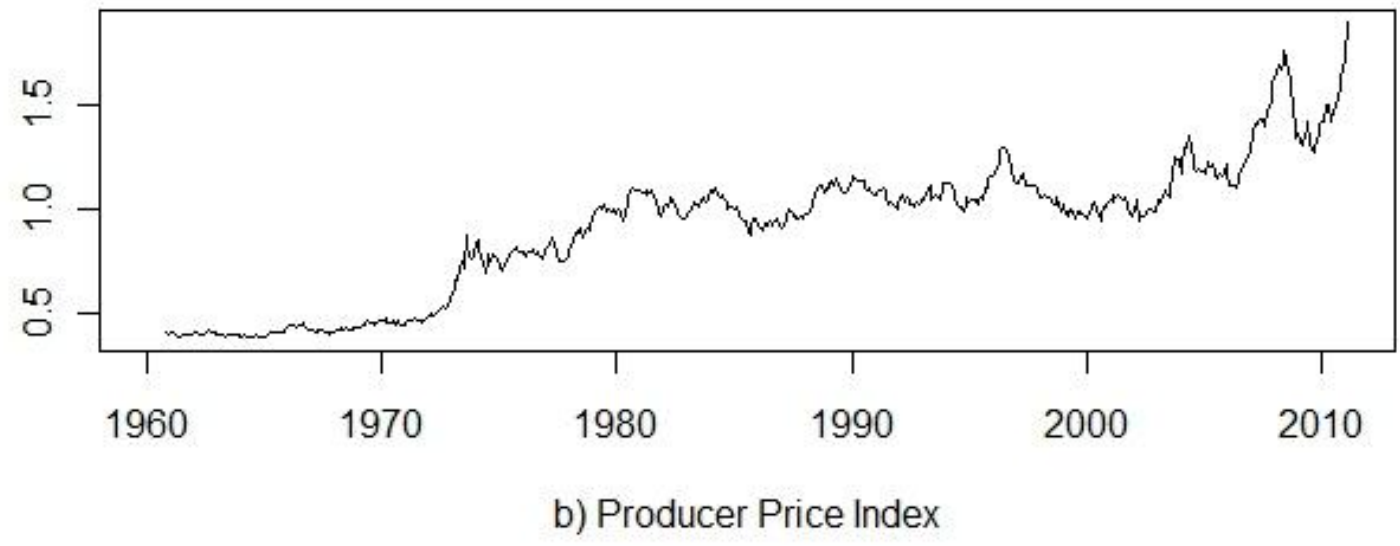

Figure 3.1: U.S. real money supply and PPI between November 1960 and February 2011

Agricultural production price indices are obtained from the U.S. Bureau of Labor Statistics ${ }^{13}$. The prices are gathered from voluntarily participating companies, and the indices are designed to measure the variation of the prices, which were realized by

\footnotetext{
${ }^{13}$ Source: http://www.bls.gov/ppi/
} 
producers for their commodities. ${ }^{14}$ Specifically, we take price series at two levels of aggregation: (1) the agricultural producer price index (PPI) as a whole (see Figure 3.1b) and (2) livestock, milk, poultry, grain, fruit and vegetable prices separately. The prices are dynamically seasonal adjusted. Therefore, the fitted values of time-varying parameters of seasonal dummy-variables, which were estimated by applying a Kalman Filter, were removed from the prices.

\subsection{Empirical Results}

\subsubsection{Unit root tests}

In order to determine the specification of the long-run neutrality test, it is necessary to estimate the order of integration of the used time series. Therefore, we applied the ADF and KPSS test on the real money supply as well as all price series (see Table 3.1). Both tests indicate integration of order one for all prices. Only the results of the ADF and the KPSS test for real money supply are contradicting. However, the latter is only significant at the $10 \%$ level. Therefore, we refer to the findings of the ADF test. Consequently, for all pairs of time series the inequation of case 3 holds; and LRD can be estimated by regressions $(3.11){ }^{15}$

\footnotetext{
${ }^{14}$ The price time series are similar to the farmgate prices of the USDA. Even the results of the long-run neutrality test, which are reported in this paper correspond to the test results, which were produced by utilizing the farmgate prices of the USDA. However, the latter are only available for some of the used commodities and for shorter time horizons. The results attained from the usage of USDA prices are available from the authors on request.

${ }^{15}$ As both variables in the tests are integrated of order one, pairs of time series might be cointegrated. We do not report results of cointegration tests, as FS show that it is neither necessary nor sufficient for long-run neutrality of nominal prices.
} 
Table 3.1: Results of a unit root and a stationarity test

\begin{tabular}{lcc|ccc}
\hline \hline & \multicolumn{2}{c|}{ ADF } & & KPSS & \\
& Level & 1st diff. & Level & 1st diff. & 2nd diff. \\
\hline \hline Real Money & & & & & \\
Supply & 6.098 & $-6.972^{* *}$ & $3.324^{* *}$ & $0.422^{*}$ & 0.019 \\
API & 1.949 & $-12.959^{* *}$ & $2.92^{* *}$ & 0.139 & \\
Livestock & 0.582 & $-16.43^{* *}$ & $2.793^{* *}$ & 0.066 & \\
Poultry & -0.106 & $-15.635^{* *}$ & $3.044^{* *}$ & 0.031 & \\
Milk & -0.105 & $-14.845^{* *}$ & $2.903^{* *}$ & 0.039 & \\
Egg & 0.116 & $-8.228^{* *}$ & $2.131^{* *}$ & 0.036 & \\
Grain & 0.563 & $-13.293^{* *}$ & $1.725^{* *}$ & 0.136 & \\
Fruit & 0.409 & $-18.558^{* *}$ & $3.126^{* *}$ & 0.168 & \\
Vegetables & -0.227 & $-19.189^{* *}$ & $3.251^{* *}$ & 0.153 & \\
\hline \hline
\end{tabular}

Note: $* *$ and $*$ indicates significance at the $5 \%$ and $10 \%$ level, respectively

\subsubsection{FS-test}

In Figures 3.2 to 3.4, we report the estimated parameter $\theta_{k}$ of regressions (3.11) for an impact up to $\mathrm{k}=150$ for both aggregated and disaggregated prices, even though the length of the long run is quite ambiguous. For instance, FS only use 30 months; and Olekalns (1996) uses 25 months. We believe that $\mathrm{k}=150$ is long enough to capture the real long-run impact of money supply. Furthermore, we display in each graph a $95 \%$ confidence interval, which is calculated with a variance adjusted for heteroscedasticity and serial correlation following the procedure of Newey and West (1987). 


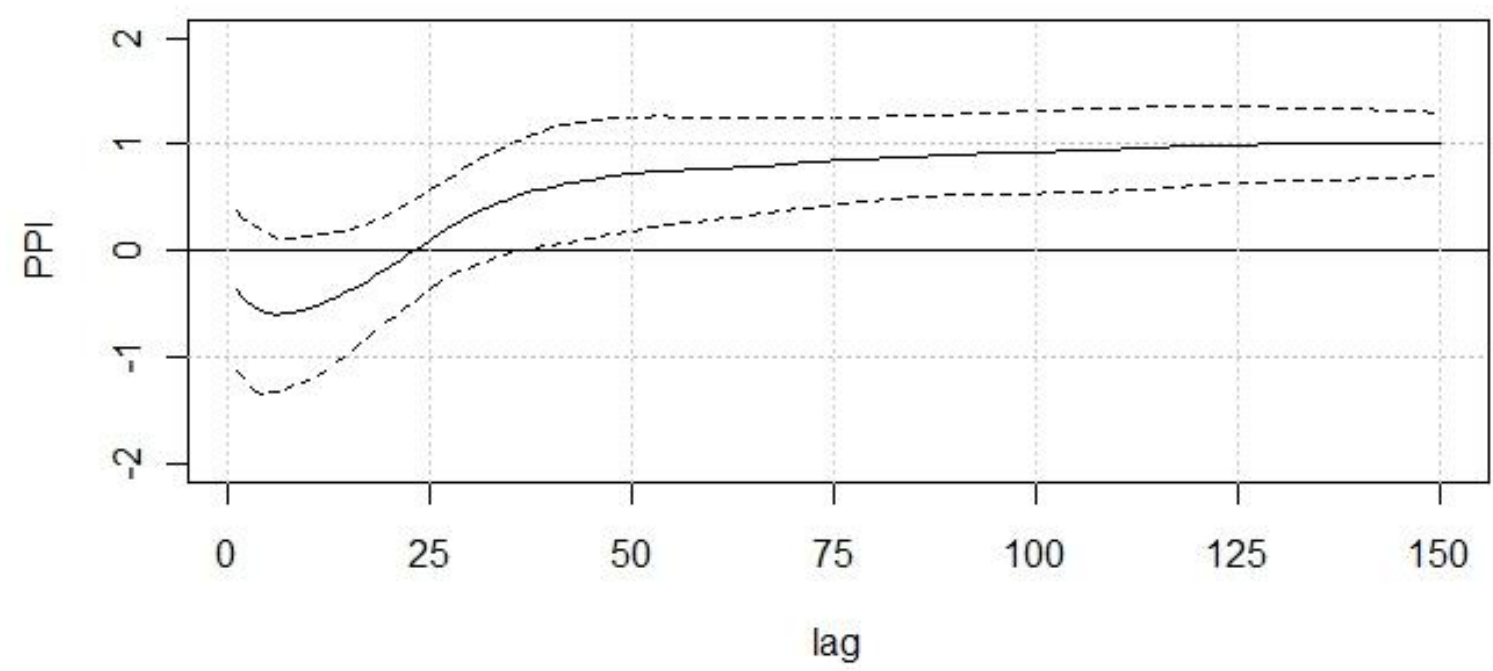

Figure 3.2: Long-run impact of real money supply on aggregated food prices

As expected, the test indicates long-run neutrality of real money supply for the PPI (Figure 3.2). The confidence intervals of the slope coefficients contain one after $k=36$. Consequently, we cannot reject the hypothesis that permanent changes in the level of real money supply are equiproportionately transferred to the level of PPI in the long run. This result is in line with most other studies in the field (Robertson and Orden, 1990; Kaabia and Gil, 2000). However, as stated before, the effect might be different in disaggregated markets because of different market characteristics, as indicated by our theoretical model. 

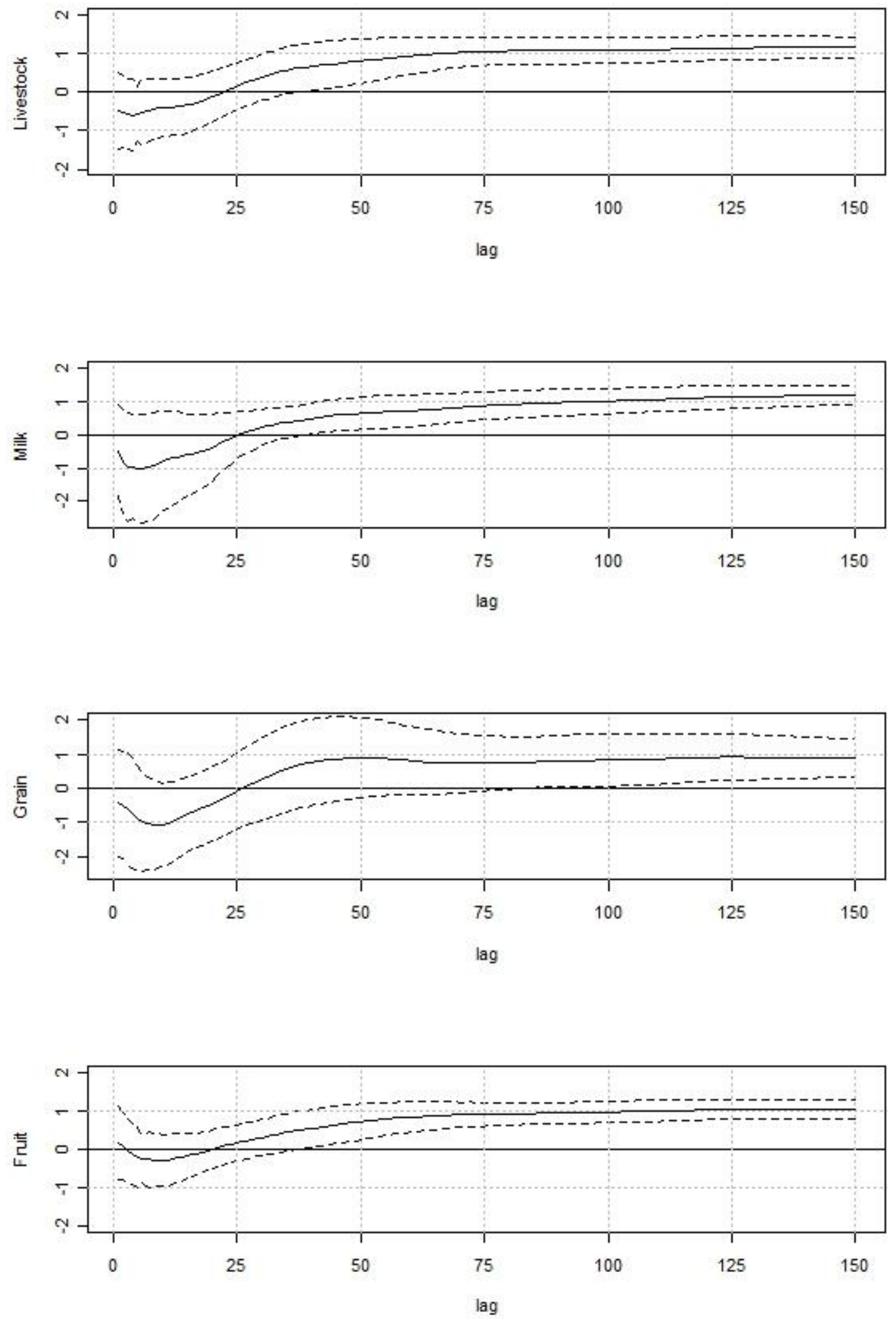

Figure 3.3: Long-run impact of real money supply on disaggregated food prices (livestock, milk, grain and fruit) 

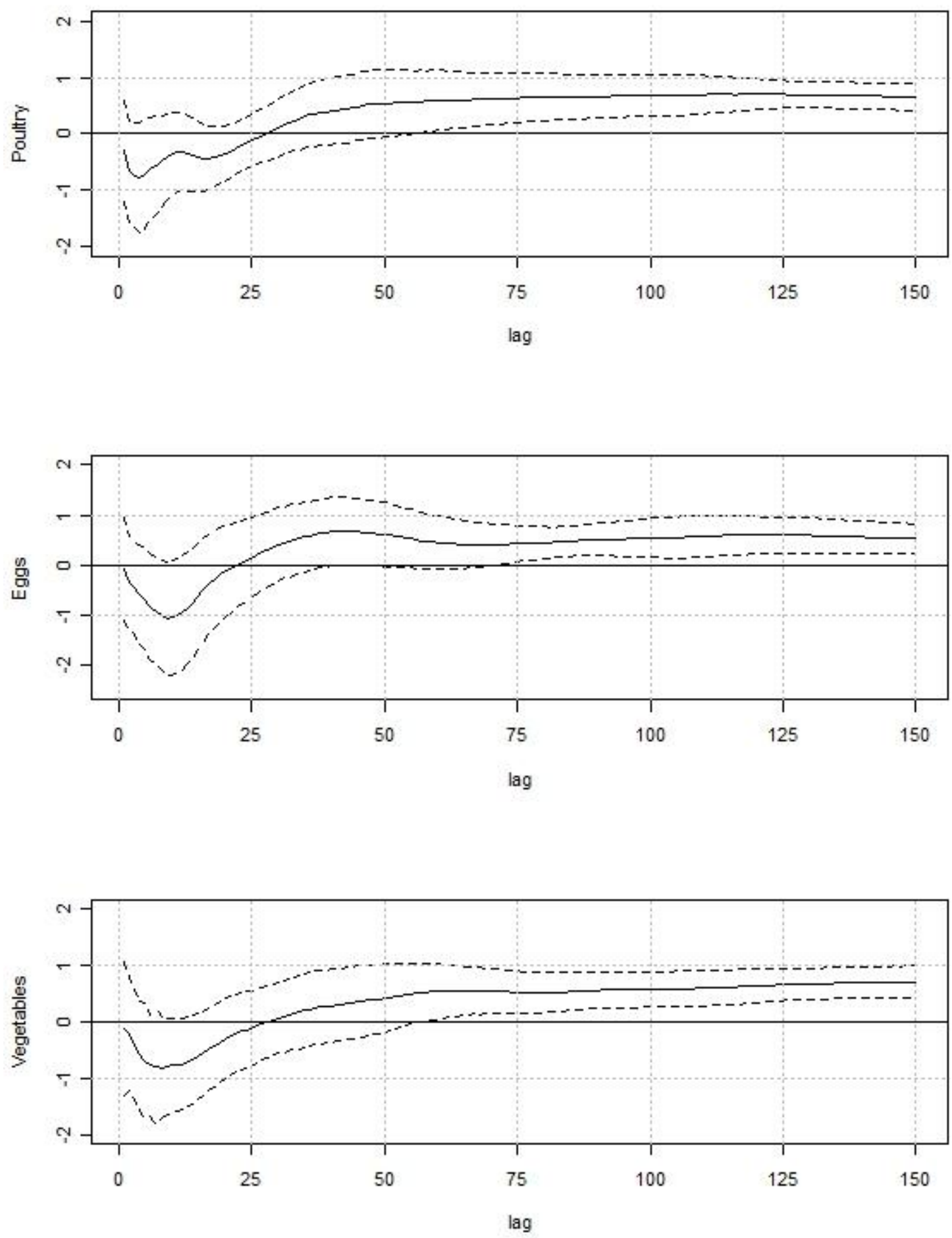

Figure 3.4: Long-run impact of real money supply on disaggregated food prices (poultry, eggs and vegetables) 
In Figures 3.3 and 3.4, we observe an adjustment of the disaggregated agricultural price parameters to a stable value in the long run. However, there are significant differences concerning the convergence to neutrality. The hypothesis of money neutrality for livestock, milk, grain and fruit, cannot be rejected. In contrast to that, we estimate that the slope parameters are significantly smaller than one for the price series of poultry, eggs and vegetables, which rejects the null hypothesis of monetary neutrality (Figure 3.4).

Comparing the empirical results with the theoretical framework in Section 3.2, we observe that the commodities with comparatively large money supply elasticities of supply are also the commodities, which are less sensitive to money supply in the long run. This outcome can be explained by a transmission of money supply shocks into agricultural markets through demand and supply shifts, which occur due to wage or trade and investment effects, respectively. Hence, from the results we can conclude that stimulated investments and eventually over proportionately rising outputs after money supply shocks induce long-run equilibriums below neutrality in markets with a more flexible long-run production. This confirms that the investment in agriculture is the determining factor of the price adjustments following expansionary monetary policies, particularly for the products whose prices are less sensitive to money supply, such as poultry, eggs and vegetables.

In the short-run, we observe a delayed response to money supply shocks, which might again result from a dominating supply response. The improved investment conditions lead to an increase in production (Devadoss, 1986) that is quicker than the balancing demand shift resulting from rising incomes.

It also indicates that the money supply eventually has important distribution effects among farmers, even though the agricultural prices as a whole is still neutral to 
money supply. Particularly for the products whose prices are less sensitive to money supply, the producers might suffer from financial loss in the long run as the price increase cannot catch up with the growth rate of money supply (inflation). Policy makers should pay particular attention to these products and make some countermeasures in advance to protect the vulnerable producers from financial loss in the long run.

\subsubsection{Robustness checks}

In order to verify the robustness of our results we conduct the long-run neutrality test for two other datasets. At first, our findings could be affected by the large peaks of the series within the last years, which are consequences of the financial crisis in 2008 and the food crisis in 2007 and 2008 (see Figure 3.1). Therefore, we tested the neutrality of the aggregated and disaggregated price indices after removing the observations from 2007 on. Figures 3.5, 3.6 and 3.7 reveal that the long-run outcomes are robust to this modification. 


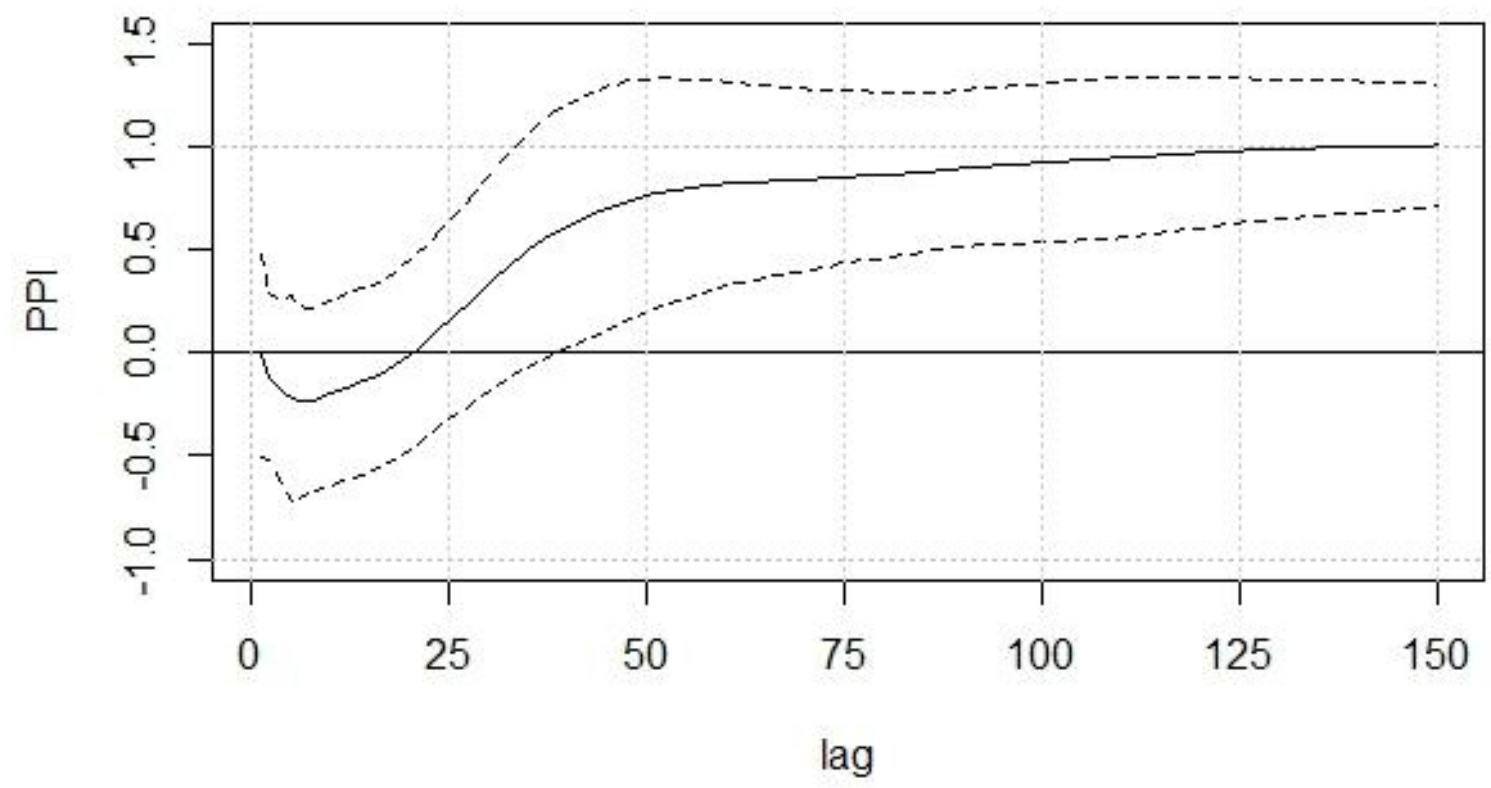

Figure 3.5: Long-run impact of real money supply on aggregated food prices before 2007 

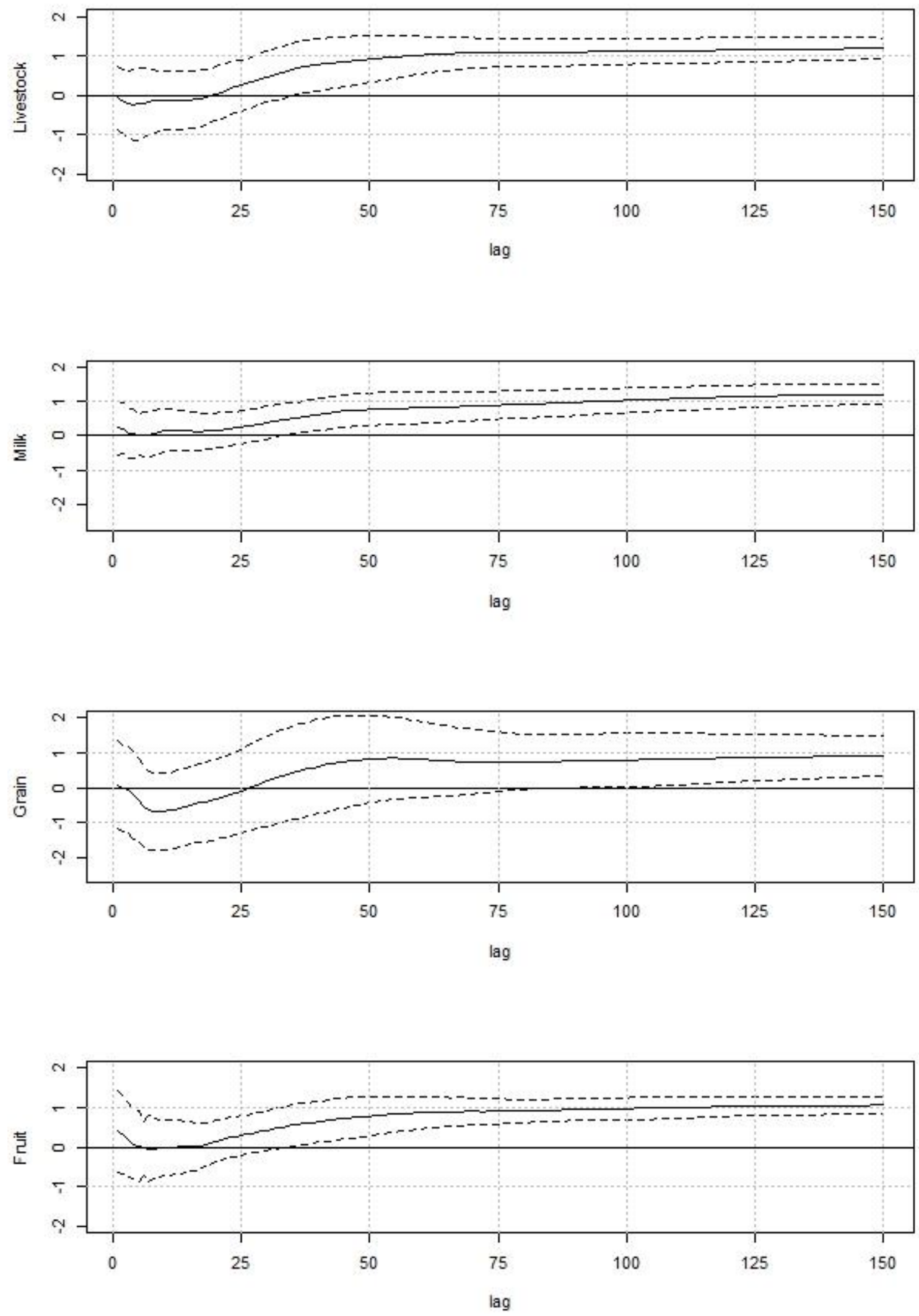

Figure 3.6: Long-run impact of real money supply on disaggregated food prices (livestock, milk, grain and fruit) before 2007 

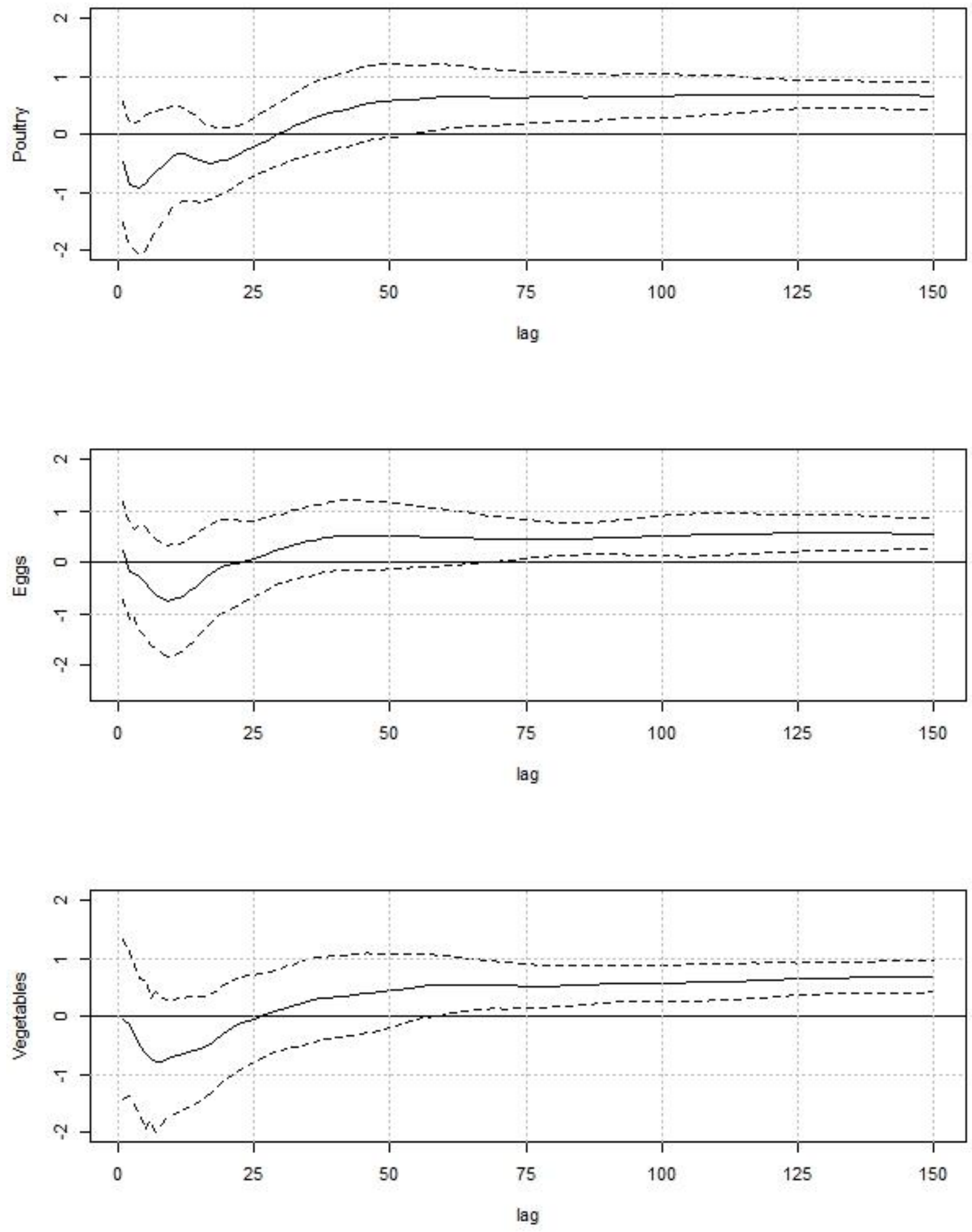

Figure 3.7: Long-run impact of real money supply on disaggregated food prices (poultry, eggs and vegetables) before 2007 
Moreover, the parameters of regression (3.11) might be different for different money aggregates. Therefore, we repeated the estimation procedure with real money supply series consisting of the M3 instead of the M2 money aggregate of the U.S. Dollar. Because the FED stopped reporting the M3 series in 2006, the dataset in this scenario covers only the time until that year. The findings in Figures 3.8 to 3.10 even more clearly reveal that the quantitative easing policy is not long-run neutral for the prices of investment elastic sectors, such as poultry, eggs and vegetables.

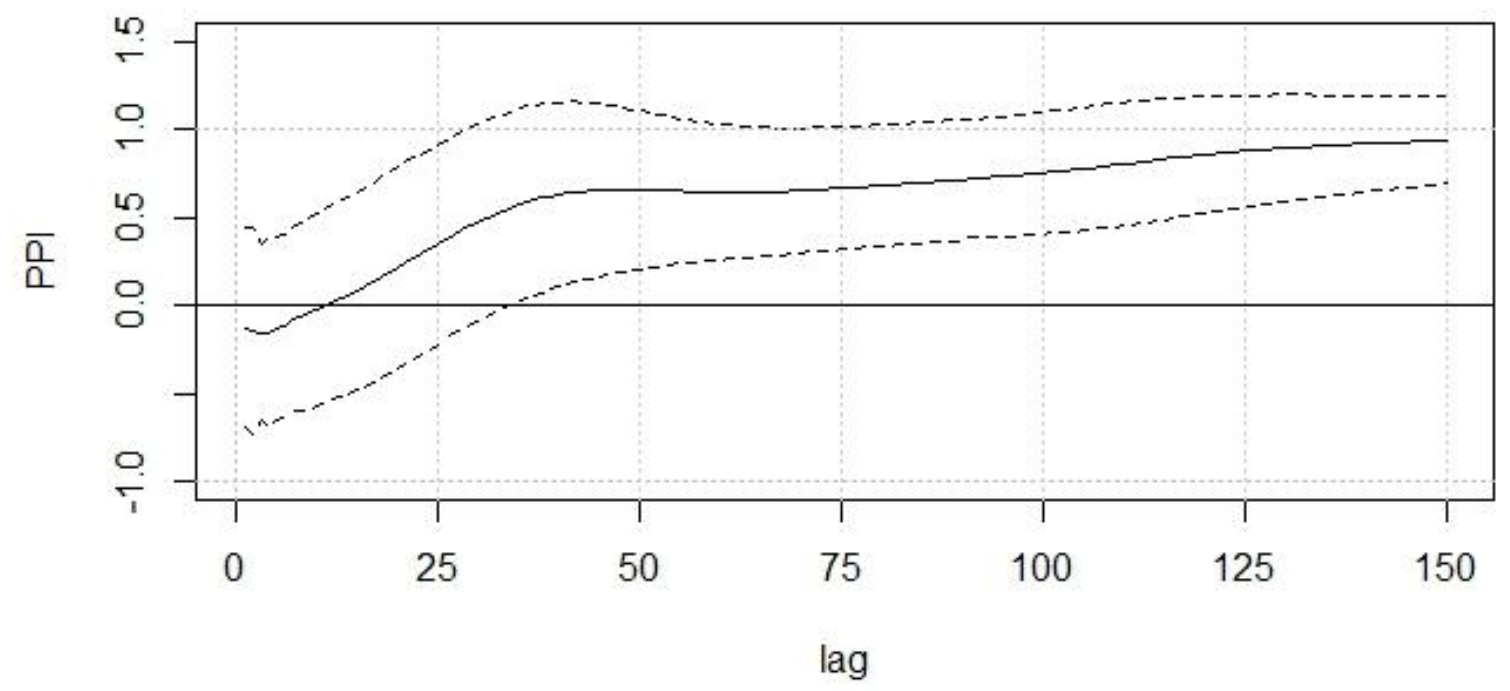

Figure 3.8: Long-run impact of real money supply (M3) on aggregated food prices 

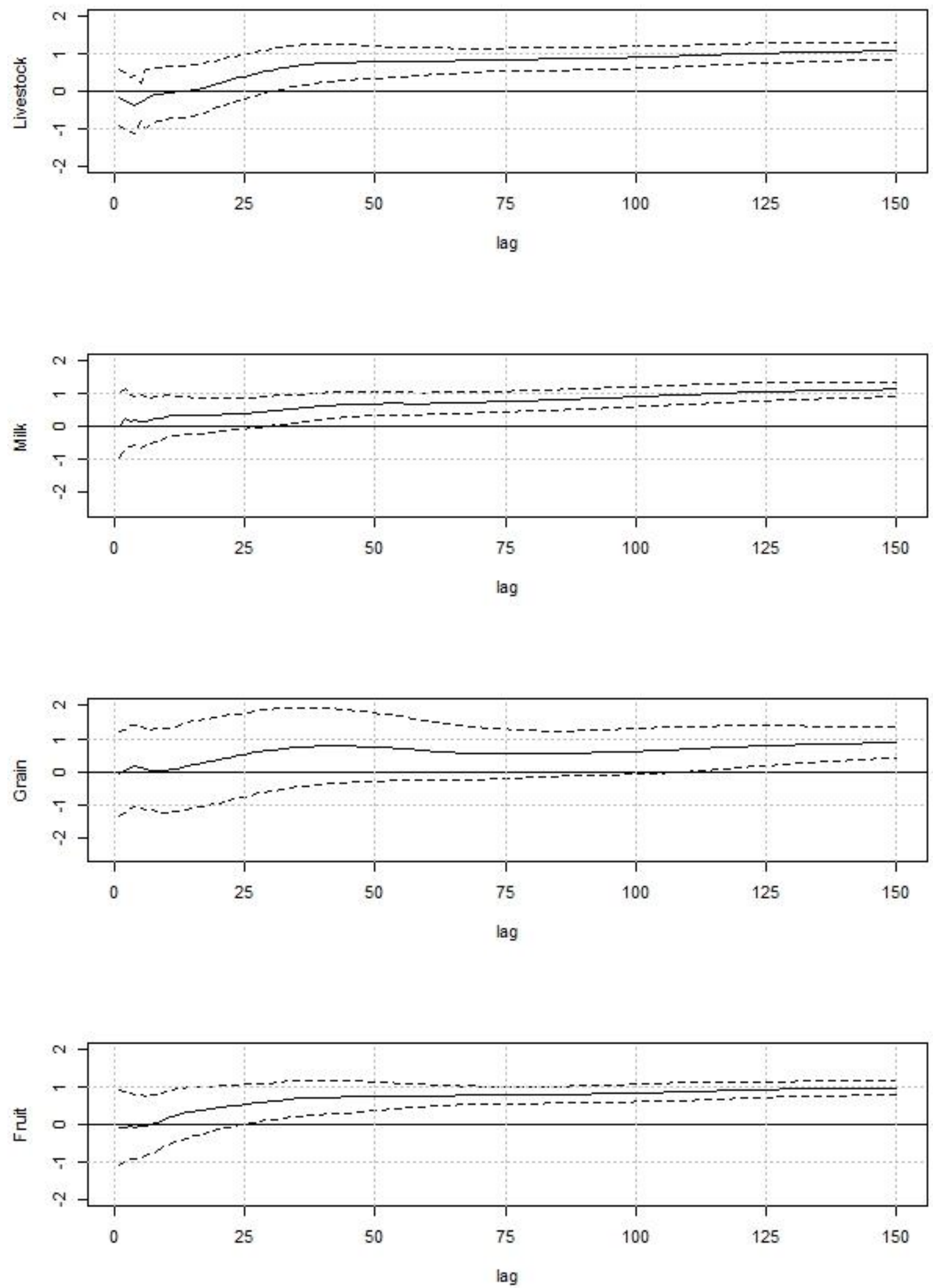

Figure 3.9: Long-run impact of real money supply (M3) on disaggregated food prices (livestock, milk, grain and fruit) 

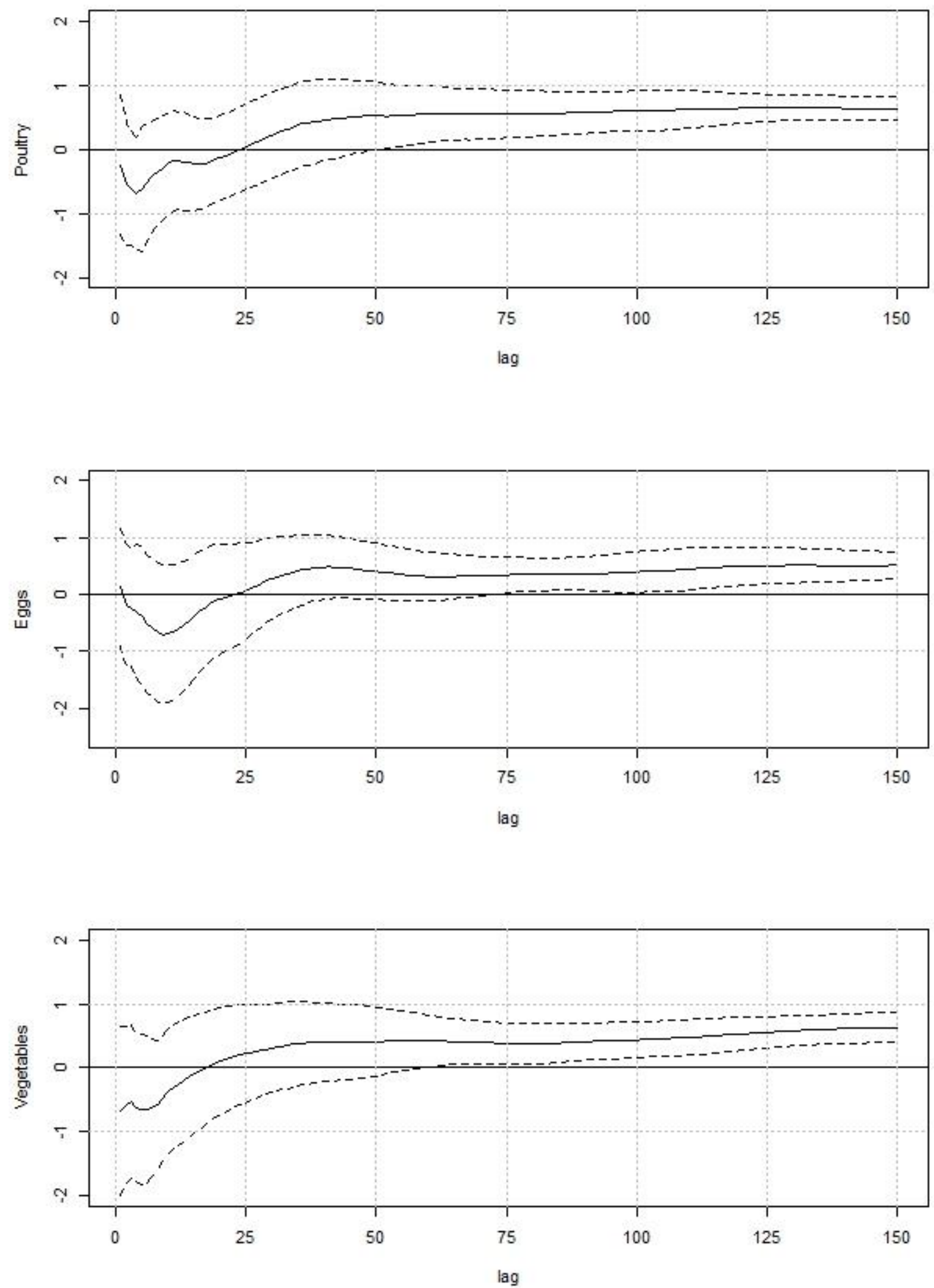

Figure 3.10: Long-run impact of real money supply (M3) on disaggregated food prices (poultry, eggs and vegetables) 


\subsection{Conclusions}

It has been known that expansionary monetary policy can result in an increase in food prices, so that a detailed analysis of monetary policy's impact on agriculture might be important to assess future problems correctly. Therefore, we attempt to shed light upon the responses of aggregated and disaggregated food prices to money supply shocks, by building up a simple theoretical framework and applying the FS procedure to test the long-run neutrality in the U.S. between 1960 and 2011.

The results of the testing procedure indicate that we cannot reject the hypothesis that the agricultural prices as a whole and most of the sub-indices are neutral in the long run with respect to changes in real money supply. The prices of poultry, eggs and vegetables, which remain below neutrality constitute exceptions. This might be caused by the fact that the markets for these three commodities exhibit a comparatively strong supply response concerning money supply changes. Because of this relationship, we can confirm that money supply shocks are transferred into agricultural markets by demand and supply shifts, and that the stimulation for farmers' investment is determining the level of the long-run equilibrium.

The long-run effects for some products are less sensitive to money supply, such as poultry, eggs and vegetables, and these producers are especially vulnerable to the expansionary monetary policy, as the price increase cannot catch up with the growth rate of money supply (inflation) particularly under the condition of large scale quantitative easing policies. The producers as well as policy makers should observe the changes in monetary policy carefully and incorporate the results of sensitivity analyses with respect to policy changes into the investment strategies, and make some countermeasures in advance to protect the vulnerable producers with less sensitive longrun price elasticity with respect to money supply from financial loss in the long run. 
4 The Convergence of the Common Livestock

Market after the Eastern Enlargement of the $E^{16}$

${ }^{16}$ This case study was jointly written with Xiaohua Yu. 


\subsection{Introduction}

There has been growing interest in advancing panel convergence tests in recent econometric literature. Many new procedures have been developed, for instance by Im et al. (2003), Proietti (2005), Busetti et al. (2007) and Pesaran (2007). In line with this trend, PS proposed a test derived from a time-varying factor model. This framework is advantageous over earlier attempts, as it involves the possibility of the analyzed time series to exhibit individual adjustment processes. Additionally, a distinguishing between non-stationary or trend stationary common trends for conducting the standard convergence test of PS is not necessary. Since the methodology is simply adaptable, it has already been applied widely across several different economic fields. For instance, PS used it to test for convergence in the cost of living between U.S. cities and of income between countries (Phillips and Sul, 2009); Panopoulou and Pantelidis (2009) investigated the world's CO2 emissions; and Fritsche and Kuzin (2011) shed light on CPIs, GDPs, labor costs and productivities in the European Union (EU). In this case study, we will expand the list of applications by important livestock prices within the EU.

Convergence, as it has been defined by PS, means that the individual trends of two (or more) time series merge into a common trend when the time domain goes to infinity. The concept can be utilized for analyses of economic models, which feature a changing long-run equilibrium as a consequence of exogenous shocks, especially if the long-run relationship underlies a narrowing or widening process. Therefore, convergence makes it possible to capture equilibrium dynamics, which cannot be explained by the heavily applied concept of cointegration, as this is defined for stable relationships. In economics, many examples of dynamic equilibriums can be found. For instance, the prices of spatially separated markets of homogenous goods, which are 
related through the law of one price, might be converging as the markets are in transition or growing together. In this case, a testing of convergence can reveal whether the transaction costs are increasing or decreasing, or whether the arbitrage mechanisms are improving or deteriorating. This assessment of changes in price heterogeneity can ex post reveal if policy measures, which were implemented to increase market integration, were successful in the long run. So far, progression in market efficiency has been mainly investigated in developing and transition countries, which can be seen in the work of Fan and Wei (2006) for instance, or that of van Campenhout (2007).

Moreover, the EU internal market might feature an unstable long-run equilibrium as well (Goldberg and Verhoven, 2005). For instance, the EU enlargement to include Eastern Europe in April 2004 was a recent exogenous change, which has heavily influenced the market structure. At that time, ten Eastern European and Mediterranean countries entered the EU which extended the market to become the largest common market in the world (measured by GDP, see IMF, 2012). As a consequence of the enlargement, the structure in the accession markets might have changed specifically with respect to regulatory, production and supply chain adjustments. ${ }^{17}$ These adaptations could lead to a prolonged catching-up process of the prices. Beyond that, the structure within all EU countries might have been affected because the adjustment of regulations reduces the corresponding transaction costs, which in turn increase marketing and consumption opportunities. ${ }^{18}$

Additionally, recent policy measures might have had an effect on the long-run equilibrium. Even though large steps towards market integration had been taken in the

\footnotetext{
${ }^{17}$ Those effects might occur, even though there were adjustments of the structure, trade agreements or trainings of the government agencies offered by the EU before.

${ }^{18}$ A similar question was also already raised in an empirical study by Solakoglu and Civan (2006) for eastern European countries before 2004. They found that the accession countries already converged significantly towards the world market.
} 
past, such as the abolition of all quotas and fiscal tariffs regarding trade between the member states (customs union) or the reduction of some non-tariff trade-barriers (e.g. common norms), the European Commission (EC) is still concerned about the heterogeneity of markets (EC, 2009a and EC, 2011) and fosters the assimilation. For instance, the EC just recently launched the European Food Prices Monitoring Tool (EC, 2009b), which publishes the price differences between the markets and therefore improves transparency.

Moreover, an important policy measure for reducing the price heterogeneity between EU countries was the introduction of the common currency. The EMU (European Monetary Union) member states immediately abolished the mutual exchange rate risk. However, not all EU countries adopted the Euro. Therefore, the different currencies might be a source of heterogeneity in prices. Especially, due to the euro crisis, the price dynamics might have become more distinct.

The integration of agricultural markets has always been very important for the member states of the EU. Therefore, they merged the organization of the sector in the CAP. Nevertheless, the developmental steps towards market efficiency have not been sufficiently analyzed in the literature so far. Fousekis (2008) investigated the dynamics of the distribution of both poultry and egg prices within the EU between 1995 and 2006. He concludes that the prices of poultry advanced towards homogeneity and that the egg prices developed divided into clubs, which were mainly formed with respect to spatial closeness.

However, the EU pork and beef markets had not yet been analyzed with regard to their progress towards market efficiency. In addition, the available information about the relationship between the country-specific prices is inconclusive. The pork market is said to be quite homogenous because of its concentration on some dominating countries 
and its liberal political structure. Several authors find a stable long-run equilibrium using cointegration tests on small samples of countries, for instance Sanjuan and Gil (2001) and Serra et al. (2006). Nevertheless, investigating a larger sample of 14 EU countries, Fousekis (2007) finds that the prices are not homogenous. The bovine market of the EU is known to be more heterogeneous due to the disturbances caused by policy measures (CAP) and a large variety of production strategies (e.g. suckler cow husbandry, bull-mast or as a side product of milk production). Because of a large number of exogenous shocks, such as policy changes, the standard cointegration measures are not applicable. Only Ihle et al. (2012), who use a methodology that is robust for break points, find cointegration between the calf prices of four EU countries.

In order to advance knowledge about the development towards price homogeneity, we analyze the pork and beef markets after the important enlargement of the EU to Eastern Europe in 2004. As already mentioned, we utilize the innovative logt-test for this purpose. However, because panels of agricultural prices are not necessarily non-stationary or trend stationary, see for instance Stigler (2011) for a discussion of this issue, we indicate an additional testing framework, which correctly estimates convergence of stationary panels. Consequently, we apply the appropriate specification of the test on panels of weekly beef and pork prices, which cover the first eight years of membership of the new member states. In addition to the tests for convergence within the EU as a whole, we shed light on the convergence of the EMU-members and the nonEMU members.

The structure of this case study is outlined as follows: In the next section, we introduce convergence tests for panels with different time series properties; Section 4.3 contains a brief description of the data; in Section 4.4 we present the empirical results; and finally we draw a number of conclusions. 


\subsection{PS convergence test}

To begin with, the procedure of PS is theoretically brought in line with the convergence literature and its advantages are summarized over other methodologies. Thereafter, we derive the convergence hypothesis for a time-varying factor model, where we discuss, beyond the standard framework, a framework for stationary panels. Finally, the corresponding specifications of the log-t-tests are explained.

\subsubsection{Integration into the literature}

Convergence tests were initially developed for the analysis of growth models. In order to describe the dynamics of this in a more precise manner, scholars distinguish between two forms of convergence: (1) Beta-convergence (or catching-up), which implies a stronger average growth in countries, which initially lagged behind (Barro and Sala-i-Martin, 1992); and (2) sigma-convergence, which describes a reduction of crosscountry distribution of income over time (Barro and Sala-i-Martin, 1995). In order to analyze the convergence of time series, scholars tested for the former mostly by applying unit root or cointegration tests (Islam, 2003), and for the latter by estimating regressions of inequality measures on trend parameters (e.g. Proietti, 2005). According to this scheme, the studies on food prices within the EU by Fousekis $(2007,2008)$ tested for beta- and sigma-convergence, respectively. The PS test encompasses these two economic concepts. Moreover, in comparison to the cointegration test of Johanson (1988), which is used in Fousekis (2007), the PS procedure can be applied to measure the aforementioned equilibrium dynamics. Furthermore, the testing framework enables to include individual heterogeneity of the time series. This implies that idiosyncratic adjustment is possible. In addition, for its application no prior distinction between nonstationarity or trend stationarity concerning the common trend is necessary. 


\subsubsection{Convergence within a time-varying factor model}

In order to obtain a testing procedure that possesses the aforementioned benefits regarding the analysis of price panels $\left(p_{i, t}\right)$ of spatially separated countries $i \quad(i \in\{1, \ldots, N\}))$ and time $t(t \in\{1, \ldots, T\})$, the log-t-test is derived from a timevarying factor model: ${ }^{19}$

$$
p_{i, t}=\delta_{i, t} \mu_{t}
$$

According to this framework, each price can be decomposed into two parts. (1) $\mu_{t}$ denotes a common trend of the time series. The existence of common trends in spatially separated markets results from the law of one price. (2) $\delta_{i, t}$ is the country's specific factor loading, which also varies over time. It can be interpreted as the distance between the idiosyncratic prices and the common trend. Price differences between spatially separated markets might result from market imperfections or transaction costs. Decreasing distance parameters, for instance as a result of policy measures, correspond to convergence of the prices. Therefore, convergence can be defined with respect to the distance parameter of the time-varying factor model:

$$
\lim _{k \rightarrow \infty} \delta_{i, t+k}=\delta
$$

\footnotetext{
${ }^{19}$ The time-varying factor model is suitable for a large number of economic models, see PS for a summary.
} 
where $\delta$ is a common parameter, which is constant over $i$ and $t .^{20}$

In order to derive a convergence test from equation (4.2), it is necessary to define the idiosyncratic distance parameter more precisely, while simultaneously allowing its structure to remain sufficiently flexible. Therefore, a time-varying form is used, which consists of both an idiosyncratic constant and a stochastic component. The latter part can again be divided into the random variable $\xi_{i, t}$, which is $\operatorname{iid}(0,1)$ over $i$ and weakly dependent over $t$ and an idiosyncratic, time-varying standard deviation $\sigma_{i, t}$.

$$
\delta_{i, t}=\delta_{i}+\sigma_{i, t} \xi_{i, t}
$$

Because the specification of the standard deviation`s adjustment process depends on the analyzed dataset`s time series properties, it is important to distinguish between two cases:

At first, PS defined the scale parameter for non-stationary and trend stationary panels. They utilized the variance function of a central limit theorem for Brownian motions, which is a regularly varying function, in order to capture the increasing variance:

$$
\sigma_{i, t}=\frac{\sigma_{i}}{L(t) t^{\alpha}}
$$

\footnotetext{
${ }^{20}$ Substituting equation (4.1) into equation (4.2), we can transform the definition of price convergence into a model-independent hypothesis: $\lim _{k \rightarrow \infty} p_{i, t+k} / p_{j, t+k}=1$, where $i \neq j, i, j \in\{1, \ldots, N\}$.
} 
where $\sigma_{i}$ is a scale parameter and $L(t)$ represents $\log (t)$ or any other slowly varying function.

However, the variance of stationary panels is finite. Therefore, the transition of the variance has to be modeled by an ordinary trend:

$$
\sigma_{i, t}=\frac{\sigma_{i}}{t^{\alpha}}
$$

From definition (4.3) and (4.4) or (4.5) we can derive a testable hypothesis of convergence because the idiosyncratic part of $\delta_{i, t}$ goes asymptotically to zero when $\alpha \geq 0$. Consequently, the testing of convergence relies on the parameter $\alpha$. The hypotheses can be formulated as follows:

$$
\begin{aligned}
& H_{0}: \delta_{i}=\delta \text { and } \alpha \geq 0 \\
& H_{1}: \delta_{i} \neq \delta \text { and } \alpha<0
\end{aligned}
$$

An acceptance of the $H_{0}$ would mean that all prices are converging to a common trend, whereas a rejection would imply that some prices are diverging. ${ }^{21}$

\footnotetext{
${ }^{21}$ Another important feature of the procedure proposed by PS is the possibility to build endogenous convergence clubs, which is worth being mentioned even if it is not used in the empirical analysis. We quoted that a rejection of the null hypothesis means that one or more units are not converging. In this case the log-t-test can be used to endogenously determine whether the time series are converging in clusters. For further details see PS.
} 
The parameter $\alpha$ displays the degree of alignment of the prices in the time period, therefore, it is called the speed of convergence. With respect to spatially separated markets, a significant non-negative convergence speed could mean that policy measures, which are supposed to improve the integration of the markets, were successful. For policy makers in the EU, it indicates a progress towards price homogeneity. Furthermore, a comparison of the parameters for different price panels makes it possible to assess the improvements. For instance, we are estimating the convergence speed in both pork and beef markets after the EU enlargement. The impact of the enlargement on the markets might be different due to a distinct awareness of marketing opportunities by the agents. Therefore, a comparison of the convergence speed can reveal to policy makers which markets are lagging behind and require additional measures.

In addition, the convergence speed can also be used to investigate the influence of specific properties of the panel units on the convergence within the panel. To do so, at first price convergence has to be confirmed for the whole sample (acceptance of the $H_{0}$ ), which would imply that the prices in the panel asymptotically follow a common trend. Afterwards, the convergence speed has to be estimated for clusters, which were formed by categorizing the countries according to the specific properties. A larger alpha parameter indicates a stronger convergence of the prices within the clusters, but also a stronger convergence to the common trend of the whole panel. In the empirical part, we utilize this approach to compare the convergence of the new and old member countries of the EU as well as that of the EMU and non-EMU members. 


\subsubsection{Log-t-test}

An estimation of the convergence speed parameter in the time-varying factor model (4.1) enlarged by equation (4.3) and (4.4) or (4.5) is not feasible, because there are too many unknowns in the system. Therefore, PS propose the utilization of the relative distance parameters to the panel mean instead of the absolute parameters. These relative parameters can be obtained from the standardized prices:

$$
h_{i, t}=\frac{p_{i, t}}{\frac{1}{N} \sum_{j=1}^{N} p_{j, t}}=\frac{\delta_{i, t}}{\frac{1}{N} \sum_{j=1}^{N} \delta_{j, t}}
$$

If the prices of the panel converge to a common trend, the relative transition paths (the mean is one by construction) are asymptotically going to one and the crosssectional variance of $h_{i, t}$ is converging to zero:

$$
\gamma_{t}=\frac{1}{N} \sum_{i=1}^{N}\left(h_{i, t}-1\right)^{2} \rightarrow 0 \text { as } t \rightarrow \infty
$$

This property will be exploited in the log-t-test. PS derived the following regression for non-stationary and trend stationary panels:

$$
\log \left(\frac{\gamma_{1}}{\gamma_{\tau}}\right)-2 \log L(\tau)=a+b \log (\tau)+u_{\tau}
$$


whereas the cross-sectional variance $\gamma_{\tau}$ is used relative to its starting value, in order to standardize the convergence path. Furthermore, the proposed slowly varying function for $L(\tau)$ is $\log (\tau+1) .^{22}$

However, the idiosyncratic distance parameters of the time-varying factor model are different for analyzing stationary panels compared to the ones in the standard framework. Consequently, in this case the slowly varying function is dropped from the test regression:

$$
\log \left(\frac{\gamma_{1}}{\gamma_{\tau}}\right)=a_{s}+b_{s} \log (\tau)+v_{\tau}
$$

If the prices are converging, the parameters $b_{n}$ and $b_{s}$ in regression (4.10) and (4.11), respectively, are equal to two times the convergence speed $\alpha$. In order to test the hypothesis of convergence, we can conduct a regular t-test on slope parameters. Whereas, the usage of autocorrelation and heteroscedasticity robust standard errors (Newey and West, 1987) is required. The test statistics of this t-test are asymptotically normal distributed. We can reject the $H_{0}$ of convergence at a 5\% significance level if $t_{b}$ is smaller than -1.65 .

\footnotetext{
${ }^{22}$ In addition, PS shorten the sample to $\tau \in\{[r T], \ldots, T\}$. PS conducted extensive Monte Carlo Simulations and found that $\mathrm{r}$ between 0.2 and $0.3 \mathrm{might}$ be appropriate to balance size and power of the test.
} 


\subsection{Data}

In order to apply the log-t-test, we use the panels of weekly pork and beef prices, which are obtained from the EC. They cover the time period from May 2004 to April 2012. This corresponds to the 8 years of membership of eight Eastern European and two Mediterranean countries. The single time series consist of 418 observations.

The descriptive statistics of pork and beef prices are reported for each member state in Table 4.1 and 4.2, respectively. Moreover, the tables contain further information on the countries, which will be used to build exogenous clusters in the empirical section. Overall, the pork panel comprises 24 countries. ${ }^{23}$ The EU classification of the analyzed pork is labeled "E", which indicates that $55 \%$ or more of the carcass has to be lean meat.

The panel of beef prices consists of 17 EU member states, Great Britain and Northern Ireland. The quality of the meat is "R3". According to the EU grading scheme, it is qualitatively good meat, which means that the overall profiles are straight, the muscle development is good and the content of fat is medium.

\footnotetext{
${ }^{23}$ The beef and pork prices were reported from the respective government to the EC. There are some countries missing in the panels because their time series were not complete. However, the panels consist of the most important countries in terms of output quantity.
} 
Table 4.1: Descriptive statistics of the pork prices and further exogenous facts of the countries

\begin{tabular}{|c|c|c|c|c|}
\hline & Mean & $\begin{array}{l}\text { Standard } \\
\text { deviation }\end{array}$ & $\begin{array}{l}\text { New Member } \\
\text { (May 2004) }\end{array}$ & Member EMU \\
\hline Denmark & 127.31 & 10.31 & & \\
\hline The Netherlands & 134.41 & 11.37 & $X$ & $X$ \\
\hline Ireland & 136.56 & 8.66 & $\mathrm{X}$ & $\mathrm{X}$ \\
\hline France & 137.03 & 11.48 & & \\
\hline Belgium & 137.73 & 10.63 & & $\mathrm{X}$ \\
\hline Poland & 141.29 & 16.38 & $X$ & \\
\hline Finland & 141.94 & 7.66 & & $X$ \\
\hline Sweden & 142.82 & 10.77 & $X$ & $X$ \\
\hline Slovenia & 144.71 & 11.06 & $X$ & \\
\hline Austria & 146.38 & 11.81 & & $\mathrm{X}$ \\
\hline Estonia & 146.83 & 9.24 & & $X$ \\
\hline Hungary & 147.65 & 12.61 & & $X$ \\
\hline Spain & 148.47 & 14.5 & & $X$ \\
\hline Czech Republic & 149.51 & 14.27 & & $X$ \\
\hline Germany & 150.45 & 12.13 & & $X$ \\
\hline Slovakia & 151.05 & 14.84 & & \\
\hline Luxembourg & 151.57 & 11.67 & $X$ & \\
\hline Lithuania & 151.76 & 14.16 & & $\mathrm{X}$ \\
\hline Portugal & 153.71 & 13.37 & & $X$ \\
\hline Latvia & 154.39 & 13.99 & $X$ & \\
\hline United Kingdom & 155.25 & 9.76 & & $\mathrm{X}$ \\
\hline Italy & 156.54 & 16.45 & & $X$ \\
\hline Cyprus & 163.92 & 18.05 & $X$ & \\
\hline Greece & 173.76 & 16.69 & $X$ & \\
\hline $\begin{array}{l}\text { Standard } \\
\text { deviation }\end{array}$ & 9.89 & 2.72 & & \\
\hline
\end{tabular}


Table 4.2: Descriptive statistics of the beef prices and further exogenous facts of the countries

\begin{tabular}{|c|c|c|c|c|}
\hline & Mean & $\begin{array}{l}\text { Standard } \\
\text { deviation }\end{array}$ & $\begin{array}{l}\text { New Member } \\
\text { (May 2004) }\end{array}$ & Member EMU \\
\hline Poland & 249.73 & 35.73 & $\mathrm{X}$ & \\
\hline Slovakia & 272.15 & 35.1 & $X$ & $\mathrm{X}$ \\
\hline Czech Republic & 278.23 & 29.7 & $\mathrm{X}$ & \\
\hline The Netherlands & 285.73 & 21.6 & & $\mathrm{X}$ \\
\hline Sweden & 286.31 & 40.07 & & \\
\hline Belgium & 289.89 & 25.04 & & $X$ \\
\hline Slovenia & 294.4 & 27.89 & $X$ & $X$ \\
\hline Ireland & 299 & 35.57 & & $X$ \\
\hline Northern Ireland & 303.13 & 33.83 & & \\
\hline Austria & 311.14 & 26.66 & & $X$ \\
\hline Germany & 312.4 & 30.97 & & $X$ \\
\hline Denmark & 316.41 & 31.92 & & \\
\hline France & 317.82 & 21.32 & & $\mathrm{X}$ \\
\hline Great Britain & 322.32 & 34.13 & & \\
\hline Spain & 323.98 & 28.52 & & $X$ \\
\hline Finland & 324.73 & 24.47 & & $X$ \\
\hline Portugal & 333.52 & 25.69 & & $X$ \\
\hline Italy & 351.16 & 23.5 & & $X$ \\
\hline $\begin{array}{l}\text { Standard } \\
\text { deviation }\end{array}$ & 24.63 & 5.44 & & \\
\hline
\end{tabular}

By comparing Tables 4.1 and 4.2, it becomes obvious that the dispersion of pork prices is much lower than the dispersion of beef prices within the EU. This also reflects our expectations that the pork market is more homogenous.

\subsection{Empirical results}

In the theoretical section, we exposed that it is necessary to determine the time series properties of the panels, in order to apply the correct specification of the log-t- 
test. Therefore, we conduct several panel unit root tests on the datasets, before we estimate the properly specified test regression.

\subsubsection{Panel unit root tests}

For robustly estimating the time series properties of the datasets, we utilized several well-known panel unit root tests. Besides the one proposed by Levin et al. (2002) (LLC), we report the results of the tests by Breitung and Das (2005) (BD) as well as Im et al. (2003) (IMP) in Table 4.3.

Table 4.3: Results of several panel unit root tests for the beef and pork prices

\begin{tabular}{lcccc}
\hline \hline & Beef & & Pork & \\
& Level & $1^{\text {st }}$ Difference & Level & $1^{\text {st }}$ Difference \\
\hline \hline LLC & 0.99 & $-42.06^{* *}$ & $-2.059^{* *}$ & $-59.08^{* *}$ \\
BD & 1.104 & $-52.35^{* *}$ & $-2.216^{*}$ & $-18.19^{* *}$ \\
IPS & 0.795 & $-47.71^{* *}$ & $-11.31^{* *}$ & $-54.76^{* *}$ \\
\hline \hline
\end{tabular}

Note: The numbers of lags are selected by the Akaike criterion. $*$ and $* *$ stands for the $5 \%$ and $1 \%$ significance level, respectively.

The findings for both panels are unequivocal. We can confirm that the panel of beef prices is non-stationary. Consequently, regression (4.10) is the correct specification for the log-t-test. In contrast to that, the convergence speed of the pork panel has to be properly estimated with equation (4.11), as the dataset consists of solely stationary time series. 


\subsubsection{Convergence tests}

After testing the convergence hypothesis for the whole EU, we also apply the log-t-test to the exogenously determined clusters. For each PS test, we list the coefficient of the corresponding regression and the corresponding t-value, which states that all prices are significantly converging to a common trend if its value is larger than -1.65 at a $5 \%$ significance level.

In Table 4.4, the results of the pork and beef prices are reported. The parameters indicate that the panel units are converging to unity. The observed heterogeneity in the descriptive statistics of the prices is reducing. Overall, we can confirm that the measures of the EC are successfully leading the markets towards efficiency. Comparing the speeds of adjustment of pork and beef prices, we find a substantial difference. The beef price's lower convergence speed indicates that there is still potential for improving the functioning of the beef market. The striking heterogeneity of the prices is a consequence of the extensive idiosyncratic policies within the countries`cattle markets. A summary of the distinct measures is reported by the EC (2012). Therefore, policy makers should focus on reducing the still existing regulatory differences between the domestic markets in order to diminish the price heterogeneity.

Table 4.4: Log-t-test for the livestock price panels of the EU member states

\begin{tabular}{lcc}
\hline \hline & $b$ & $t_{b}$ \\
\hline \hline Pork & 0.284 & 4.067 \\
Beef & 0.0932 & 2.184 \\
\hline \hline
\end{tabular}

In order to evaluate further details of the asymptotic long-run equilibrium, we split the panel of the EU countries into different clusters and separately apply the log-t- 
test to the clusters. At first, we look at the new members and the old members. Afterwards, we divide the sample into EMU members and non-EMU members.

We present the subgroup results in Table 4.5. The larger convergence speed parameters of the new members as compared to the ones of the old members confirm that the former are converging more strongly because of the adjustments to the EU regulations and maybe stronger trade among themselves. Furthermore, according to an overall common trend, which was confirmed in Table 4.4, we can state that the prices of the new members experience a catching-up process. Moreover, comparing the convergence speed parameter for the accession countries, we find that the pork prices are adjusting more strongly than the beef prices. Obviously, the producers in the a priori more integrated pork market, which are mainly highly efficient large-scale operations, are faster and further exploiting the profit opportunities from the enlargement. In the more segmented beef market, the heterogeneity seems to slow down the realization of the new marketing opportunities. Therefore, policy makers should specifically focus their efforts regarding price harmonization on the beef market and other segmented markets in the accession countries.

Table 4.5: The results of log-t-tests on subsamples of the price panels

\begin{tabular}{lcccc}
\hline \hline & Pork & \multicolumn{3}{c}{ Beef } \\
& $b$ & $t_{b}$ & $b$ & $t_{b}$ \\
\hline \hline Accession countries & 0.571 & 7.351 & 0.165 & 1.754 \\
Old Member States & 0.207 & 1.637 & 0.0287 & 0.621 \\
EMU & 0.275 & 3.114 & 0.129 & 4.184 \\
Non-EMU & 0.111 & 1.522 & -0.101 & -1.049 \\
\hline \hline
\end{tabular}

Additionally, we observe that the common currency of the EMU members also contributes to a stronger adjustment of the prices. The common currency fulfills its task 
of harmonizing the markets. Moreover, it contributes to the welfare of producers and consumers in the Eurozone because it significantly reduces the possibility of arbitrage.

In Figure 4.1, we present more details regarding our findings by reporting the mean transition paths of the clusters. In all four graphs, the heterogeneity of the prices is apparently decreasing after 2009. This indicates that the European Food Prices Monitoring Tool, which was implemented at that time is successfully reducing the price heterogeneity. Additionally, the upper left graph clearly reveals the catching-up process of the new member states. Especially at the beginning of the sample, the transition path of the accession countries is strongly increasing. The dynamics in the pork prices are less visible, maybe due to the a priori stronger integration. Comparing the final distances of the transition paths in those two graphs, it again becomes apparent that policy makers should specifically focus on the beef market, as the differences in this sector are the most severe. Nevertheless, in both figures containing beef prices, we can observe a period of increasing market integration starting at the beginning of 2007. At that time, the last market disturbing policy measures, which were particularly unevenly distributed over the countries' cattle markets, were abolished in the EU by the MidTerm Review. Hence, the decoupling and harmonization of the payment scheme reduced the price differences. Furthermore, in the lower graphs, the mean transition paths are strongly diverging around 2009 due to the euro crisis. At that time the Euro was depreciating markedly compared to nearly all other currencies. 

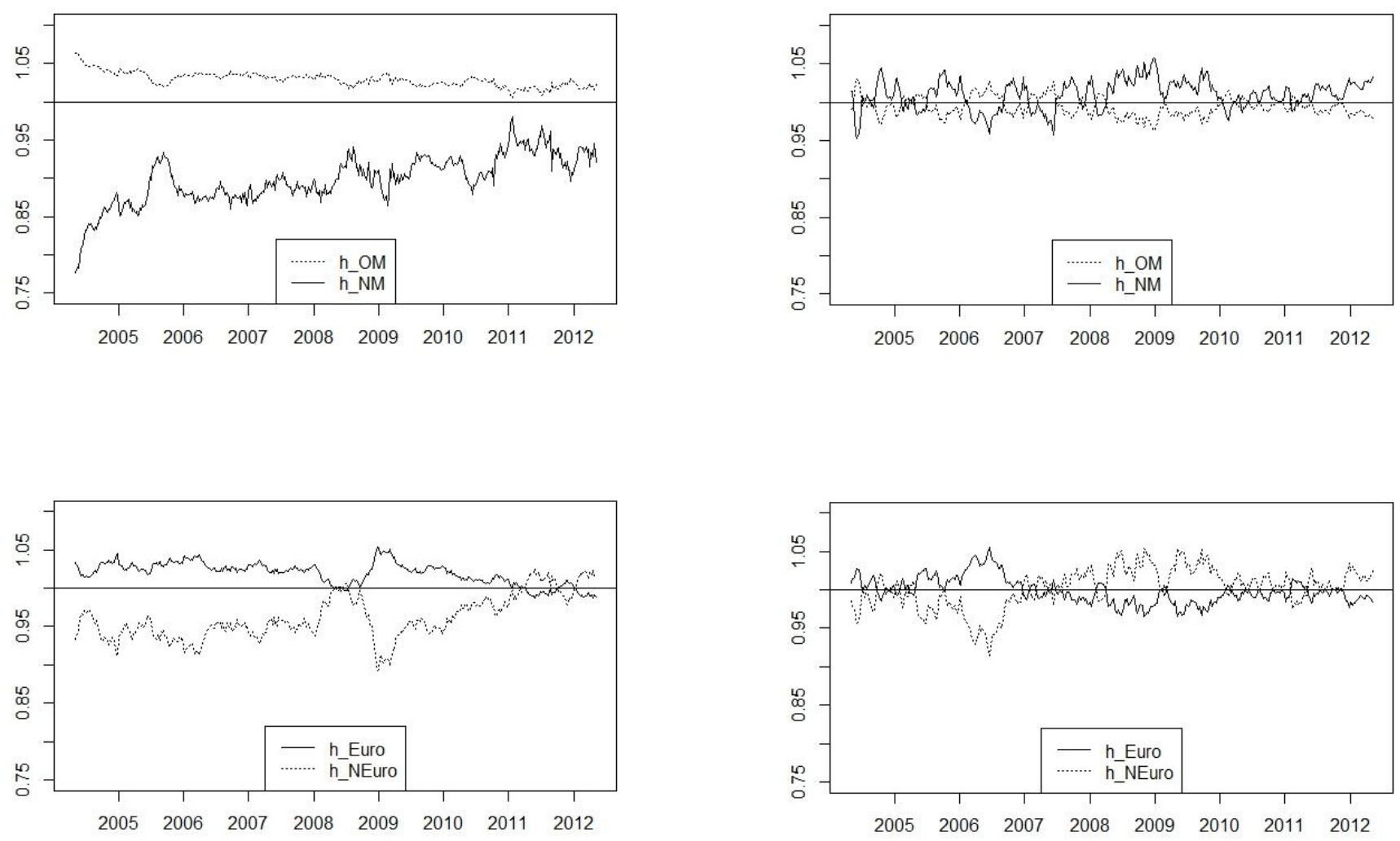

a) Beef

b) Pork

Figure 4.1: Mean $h_{i, t}$ series of different subsamples of the price panels

Another interesting feature of the bottom left graph of Figure 4.1 is that the transition paths are switching their positions with respect to unity at the end of the observation period. Specifically, the prices of the EMU countries are falling compared to those of the non-EMU countries. This can be explained by changing consumption patterns in the member states of the Eurozone, which have suffered from large budget deficits. The reduced government spending and the unpleasant economic atmosphere drove the consumers to reduce the demand for beef. The changes of the trend in food consumption expenditures can be seen in Figure 4.2, which displays standardized time series of highly indebted countries in the Eurozone. 


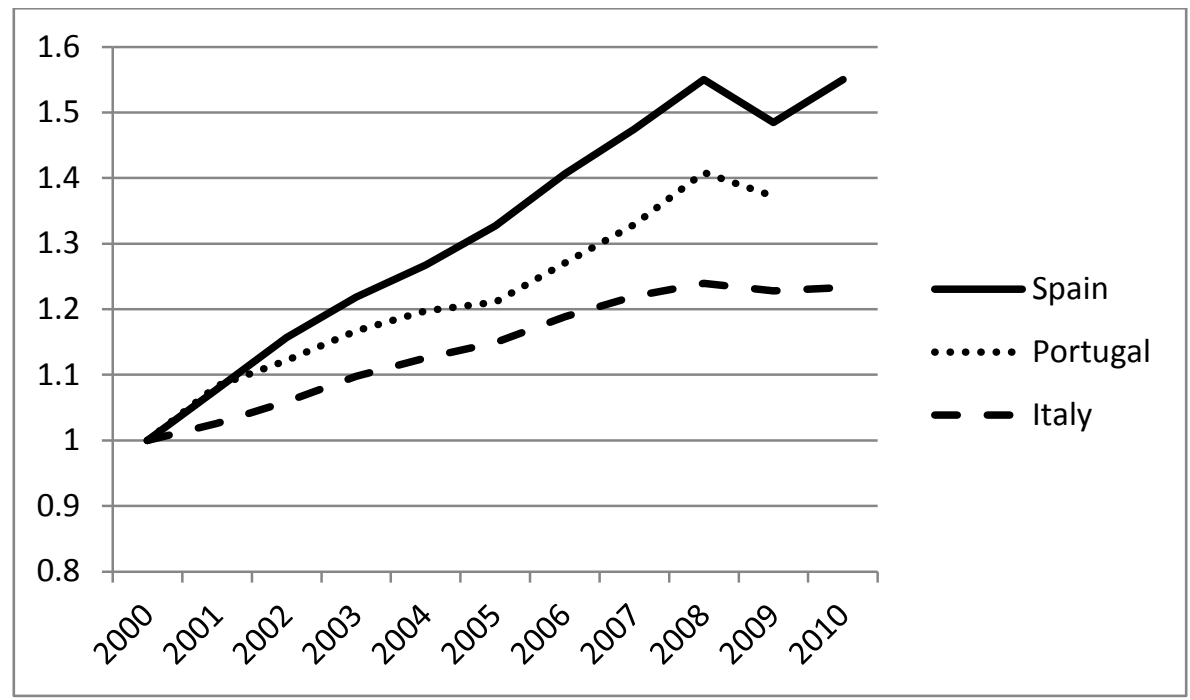

Figure 4.2: Standardized food consumption expenditure of households in three member states of the EMU, which were affected by the euro crisis (Source: OECD.Stat)

\subsection{Conclusions}

Panel convergence tests are designed to investigate if a number of time series are approaching over time to a common trend. PS recently proposed such a procedure, which stands out because it does not rely on common adjustment paths of the time series. Furthermore, for the standard test, it is not necessary to distinguish if the common trend is non-stationary or trend stationary. Additionally, the framework can be used for analyzing stationary datasets, after slightly modifying the specification of the test regression, as we show in this case study. With respect to spatial separated commodity markets, the procedure is able to indicate developments towards market efficiency. Therefore, the procedure can deliver policy relevant information for the EU internal market. The long-run equilibrium in this market is altering because of the EU enlargements and the aim of the EC to improve homogeneity of the markets. 
In this case study, we are applying the corresponding specifications of the PS test in order to analyze the convergence of the EU livestock markets of pork and beef. The sampling period covers exactly the time after the important EU enlargement to Eastern Europe in 2004. Furthermore, we look at the membership of the Eurozone, since the distinct currencies within the EU might lead to price heterogeneity.

The estimation results reveal that the overall price heterogeneity is reducing within the EU for both beef and pork. Accordingly, we can confirm that exogenous changes, such as the enlargement and policy measures (European Food Monitoring Tool and Mid-Term Review) improved the functioning of the internal markets. The persisting larger heterogeneity of the beef prices is the result of the still remaining differences of policy measures within the member states of the EU. An entire adjustment of the policies is necessary to completely harmonize the prices. Focusing on the analysis of the EU enlargement in 2004, we find a stronger convergence of the prices of the new member states compared to the old member states, which confirms that the accession countries are catching-up. Nevertheless, the prices in the more segmented beef markets of the accession countries were less strongly progressing towards homogeneity. The disturbance of the prices is still clearly observable after 8 years. Therefore, policy makers should specifically focus their efforts to improve the price homogeneity on the more segmented sectors in the accession countries. For instance, the EU could promote the access of the more efficient producers of beef from the new member states to the marketing capacities in the old member states. A detailed study of the EMU and nonEMU countries indicates that the dropping of the currency risk has indeed had an influence on agricultural markets. The countries within the Eurozone converge faster than the other countries, which significantly reduced the welfare losses of consumers and producers. Concerning the on-going euro crisis, we also find interesting results. At 
the beginning of the crisis the prices within the EU only temporarily dispersed, but then converged again. Moreover in the beef market, we reveal indications that the crisis changed the consumption behavior in the Eurozone. 


\section{Overall conclusions}




\subsection{Theoretical conclusions}

This thesis discusses causality and convergence in economic long-run equilibriums. Furthermore, econometric estimation methods, which address these issues, are presented since large parts of the literature, specifically of the literature with respect to food prices, disregard these issues.

In order to correctly investigate the long-run equilibrium of a system, it is necessary to incorporate the causality structure of the variables. For instance, food markets might be affected by different exogenous variables, such as macroeconomic or policy variables, which have an influence on food prices but not vice versa.

Moreover, many long-run equilibriums might be not stable. For instance, the relationships of the variables could be influenced by exogenous factors, which would result in a process of change. If this process leads to a tightening of the relationship between two variables, e.g. a faster return to an equilibrium after a shock to the system, this equilibrium can be analyzed drawing on the concept of convergence. In food markets, exogenous impacts, which have an impact on the long-run equilibrium, are for instance policy changes, economic transitions or market enlargements.

In this thesis, two econometric procedures are employed, which enable an implementation of causality and convergence in the estimation of long-run equilibriums. The first is the FS test for long-run neutrality, which estimates the response of one variable to the exogenous shocks of another variable. The second methodology is the panel convergence test of PS, which measures the asymptotic adjustment of the time series in the panel to a common trend. From the discussion and the case studies we derive the following theoretical conclusions for an application of the two frameworks in the context of food markets. 


\subsubsection{Comparison of Procedures}

In the literature on the analysis of long-run equilibriums of food prices usually methodologies are applied, which are based on the concept of cointegration. These models commonly assume that the market variables are endogenous. For cases with a clear causality structure the results from the FS procedure are more reliable as they introduce further information into the estimation.

The FS procedure, as it is applied in Section 2, is enlarged by additional exogenous variables. It is superior to the standard model, as it simultaneously enables the estimation of two exogenous variables on one endogenous variable.

The PS test also has several advantages over other tests. In particular, it encompasses both beta- and sigma-convergence. The advantages over cointegration tests, which are often used for the investigation of beta-convergence, are: (1) the PS test identifies the dynamics of an equilibrium (2) Idiosyncratic adjustments of the time series in the dataset are possible. (3) There is no distinguishing necessary between nonstationary and trend stationary common trends.

\subsubsection{Investigating food prices}

The application of the FS test is appropriate for the analysis of the effects of macroeconomic variables, such as money supply, on food markets because, in this case, the causal relationship is clear. Further research could include analysis of the response of food prices to other macroeconomic variables, such as exchange rates or energy prices.

Since this thesis proposes an enlargement of the procedure of PS, which enables estimating the convergence of stationary panels as well, the test is applicable for any 
structure of the common trend. The enlargement is especially important for analyzing food prices since the corresponding theory is ambiguous with respect to the time series properties of food prices (see Section 1.2). Hence, the test can now be applied to all other topics concerning food prices as well, including for instance vertical price analyses.

\subsection{Empirical and policy conclusions}

The aforementioned procedures were applied to three case studies investigating the long-run equilibriums of food markets. The first case study analyzed the impact of money supply and agricultural policy changes on food prices in Germany. The second case study in turn investigated the response of U.S. agricultural commodity prices to expansionary monetary policies. The third case study focused on the convergence of livestock markets in the EU.

\subsubsection{Long-run impact of money supply on food prices}

The results of both studies on the impact of money supply on food prices indicate that aggregated prices are neutral. Nevertheless, there are real effects on disaggregated food prices. In Germany the prices of staple foods, such as wheat, are experiencing strong increases. This is a consequence of price spikes, which result from speculators investing excess money into storable commodities. Moreover, because the demand does not adjust due to small demand elasticities, the prices remain on a high level. In contrast to that the livestock prices are not strongly affected, which is a consequence of a faster adjustment of production and a more elastic demand. In the U.S., most disaggregated prices adjust proportionate to money supply changes. Only the 
prices of poultry, eggs and vegetables remain significantly below neutrality. This could be a result of overproportional investments into these sectors and in turn a rising production in the long run.

In addition, a structural model, which explains the long-run impact of money supply on food prices, is derived. It reveals that the response of a food price to money supply changes is dependent of the relative demand and supply elasticities.

In the case study about the U.S., exactly this is confirmed. The prices in markets, which are characterized by a large supply elasticity with respect to money supply, are significantly below neutrality. Therefore, the results confirm that an increasing money supply causes positive supply and demand shocks due to investments and increasing wages, respectively.

In Germany, the strong positive impact on staple food prices is mostly driven by demand shocks, which result from speculation or trade, and is also in line with the model.

\subsubsection{EU market integration}

The analysis of the EU beef and pork markets reveals that the heterogeneity of prices within the EU is decreasing. This indicates that the markets are further integrating. A separate investigation of the prices of the new member states reveals their catching-up process. Additionally, the more segmented beef markets of the accession countries are adjusting less strongly than their pork markets. The latter are to a larger extent characterized by large-scale operations, which might be able to exploit profit opportunities quickly. In addition, comparing the heterogeneity reduction of the prices 
in the EMU member states with the reduction in the non-members reveals that the common currency contributes to an increasing market efficiency.

\subsubsection{Crises}

The results of the analyses on the impact of money supply on food prices are quite clear. There are real long-run effects in disaggregate markets. Therefore, the quantitative easing policies following the financial crisis of 2008 will likely have strong

effects on the U.S. poultry, eggs and vegetables markets. As the prices of those markets increase more slowly than the inflation rate, the producers should consider monetary policy changes in their investment strategies. Furthermore, the U.S. government should observe the price developments in those sectors carefully.

With respect to the Eurozone extreme effects on future prices as a result of the expansionary monetary policies, which are intended to solve the euro crisis, can be expected. The policy makers should particularly pay attention to the staple food prices and implement measures to prevent pronounced price spikes. Furthermore, the results of the PS convergence test show, that the EU livestock markets were additionally affected by short-run disturbances at the beginning of the crisis.

\subsubsection{Further policy conclusions}

The case study analyzing the livestock prices of the EU, confirms that the European Food Monitoring Tool, which was implemented by the EC to reduce the price heterogeneity was successful. In addition, there is potential for further reductions of price disturbances in the beef markets of the new member states. Therefore, the EC should devise measures to exploit this potential of integration. 
Additionally, the case studies revealed important results regarding the CAP. In both studies dealing with European markets, the findings confirm that the liberalization of the livestock markets due to the Mid-Term Review lead to an increase in market integration. 


\section{References}

Awokuse, T.O. (2005). Impact of Macroeconomic Policies on Agricultural Prices.

Agricultural and Resource Economics Review 34:226-237.

Barnett, B. J. (2000). The U.S. Farm Financial Crisis of the 1980s. Agricultural History $74: 366-380$.

Barnett, R. C., Bessler, D. A. and Thompson, R. L. (1983). The Money Supply and Nominal Agricultural Prices. American Journal of Agricultural Economics, 65: 303307.

Barro, R. J. and Sala-i-Martin, X. (1992). Convergence. Journal of Political Economy 100: $223-51$.

Barro, R. J. and Sala-i-Martin, X. (1995). Economic Growth, McGraw Hill, New York.

Bentzen, J. (2005). Testing for catching-up in time-series convergence. Economics Letters 88: 323-328.

Bernard, A. B. (1991). Empirical implications of the convergence hypothesis. Working. Center for Economic Policy Research. Stanford University.

Bernard, A. B. and Durlauf, S. N. (1995). Convergence in international output. Journal of Applied Econometrics 10: 97- 108.

BMELV (2005). Die EU-Agrarreform - Umsetzung in Deutschland.

Bundesministerium für Ernährung, Landwirtschaft und Verbraucherschutz. Policy Report. Berlin: BMELV. 
BMELV (2006). Meilensteine der Agrarpolitik - Umsetzung der europäischen Agrarpolitik in Deutschland. Bundesministerium für Ernährung, Landwirtschaft und Verbraucherschutz. Policy Report. Berlin: BMELV.

Bordo, M.D. (1980). The Effects of Monetary Change on Relative Commodity Prices and the Role of Long-Term Contracts. Journal of Political Economy 88:1088-1109.

Boschen, J. F.and Otrok, C. M. (1994). Long-Run Neutrality and Superneutrality in an ARIMA Framework: Comment. American Economic Review 84: 1470-73.

Bullard, J. (1999). Testing Long run Monetary Neutrality Propositions: Lessons From the Recent Research. Federal Reserve Bank of St. Louis Review 1999: 57-78.

Busetti, F., Forni, L., Harvey, A. and Venditti, F. (2007). Inflation convergence and divergence within the European Monetary Union. International Journal of Central Banking 3: 95- 121.

van Campenhout, B. (2007). Modelling trends in food market integration: Method and an application to Tanzanian maize markets. Food Policy 32: 112-127.

Carrion-i-Silvestre, J. L. and German-Soto, V. (2009). Panel data stochastic convergence analysis of the Mexican regions. Empirical Economics 37: 303-327.

Chambers, R. G. (1984). Agricultural and Financial Market Interdependence in the Short Run. American Journal of Agricultural Economics 66: 12-24.

Chambers, R. G. and Just, R. E. (1982). An Investigation of the Effect of Monetary Factors on Agriculture. Journal of Monetary Economics 9: 235-47. 
Chen, S.-S. and Chou, Y.-H. (2010). Exchange Rates and Fundamentals: Evidence from Long-Horizon Regression Tests. Oxford Bulletin of Economics and Statistics 72: 6388.

Choe, Y.C. and W.W. Koo, 1993. "Monetary Impacts on Prices in the Short and Long Run: Further Results for the United States." Journal of Agricultural and Resource Economics 18:211-224.

Cuddington, J. T. \& Urzua, C. M. (1989). Trends and cycles in the net barter terms of trade: a new approach. Economic Journal 99: 426-442.

Datta, A. (2003). Time-series tests of convergence and transitional dynamics. Economics Letters 81: 233-240.

Deaton, A. and Laroque, G. (1992). On the behaviour of commodity prices. Review of Economic Studies 59: 1-23.

Deutsche Bundesregierung (2007). Tierschutzbericht 2007. Unterrichtung durch die Bundesregierung. Drucksache 16/5044.

Devadoss, S. (1991). Tests of Monetary Neutrality on Farm Output. Western Journal of Agricultural Economics 16: 163-173.

Dolado,J. J., Gonzalo, J. and Marmol, F. (2003). Cointegration. in Baltagli, B. H. A companion to theoretical econometrics. Blackwell. Malden.

Dorfman, J. H. and Lastrapes, W. D. (1996). The Dynamic Responses of Crop and Livestock Prices to Money-Supply Shocks: A Bayesian Analysis Using Long run Identifying Restrictions. American Journal of Agricultural Economics 78: 530-541. 
Dornbusch, R. (1976). Expectations and Exchange Rate Dynamics. Journal of Political Economy 84:1161-1176.

Engle, R.F., and C.W.J. Granger (1987). Co-integration and error correction:

Representation, estimation and testing. Econometrica 55: 251-76.

Ezekiel, M. (1938). The Cobweb Theorem. The Quarterly Journal of Economics 52: 255-280.

Evans, P. (1998). Using panel data to evaluate growth theories. International Economic Review 39:295-306.

European Commission (EC) (2009a). A better functioning food supply chain in Europe. European Comission - Memo/09/483.

European Commission (EC) (2009b). A European Food Prices Monitoring Tool - A first design. European Comission - Report.

European Commission (EC) (2011). The single market through the eyes of the people: a snapshot of citizens' and businesses' views and concerns. European Comission - Press Release.

European Commission (EC) (2012). Agriculture in the European Union - Statistical and economic information report 2012. url: http://ec.europa.eu/agriculture/statistics/agricultural/2012/pdf/c6-1-361_en.pdf Fackler, P.L. and Goodwin, B.K, (2001). Spatial price analysis. in Gardner, B. L. and Rausser, G. C., Handbook of Agricultural Economics Volume 1 B. Elsevier.

Fahlbusch, M., Bahr, A., Brümmer, B. and Spiller, A. (2010). Der Markt für Milch und Milcherzeugnisse. German Journal of Agricultural Economics 59: 45-62. 
Fama, Eugene (1965). The Behavior of Stock Market Prices. Journal of Business 38: 34-105.

Fan, C. S. and Wei, X. (2006). The law of one price: evidence from the transitional economy of China. The Review of Economics and Statistics 88:682-697.

Fischer, S., 1977. "Long-Term Contracts, Rational Expectations, and the Optimal Money Supply Rule.” The Journal of Political Economy 85:191-205.

Fisher, M. E. and Seater, J. J. (1993). Long run Neutrality and Superneutrality in an ARIMA Framework. American Economic Review 83: 402-15.

Frankel, J. (1986). Expectations and Commodity Price Dynamics: The Overshooting Model. American Journal of Agricultural Economics 68: 344-348.

Fousekis, P. (2008). Price convergence in the EU poultry and eggs markets. Economics Bulletin 3:1-11.

Fousekis, P. (2007). Multiple markets within the EU? Empirical evidence from pork and poultry prices in 14 EU member countrties. Economics Bulletin 3:1-12.

Fritsche, U. and Kuzin, V. (2011). Analysing convergence in Europe using non-linear single factor model. Empirical Economics 41:343-369.

Gertler, M. and S. Gilchrist. 1994. „Monetary Policy, Business Cycles, and the Behavior of Small Manufacturing Firms" Quarterly Journal of Economics 109:309-340.

Geweke, J. F. (1986) The Superneutrality of Money in the United States: An Interpretation of the Evidence. Econometrica 54: 1-21.

Gilbert, L.C. (2010). How to Understand High Food Prices. Journal of Agricultural Economics 61:398-425. 
Golosov, M., and Lucas. R.E.Jr. (2007). Menu Costs and Phillips Curves. Journal of Political Economy 115:171-199.

Goldberg, P. K. and Verboven, F. (2005). Market integration and convergence to the law of one price evidence from the European car market. Journal of International Economics 65:49-73.

Goodwin, B. K. (1992). Multivariate Cointegration Tests and the Law of One Price in International Wheat Markets. Applied Economic Perspectives and Policy 14: 117-124.

Granger, C.W.J. (1980). Testing for causality: A personal viewpoint. Journal of Economic Dynamic Control. 2: 329-352.

Granger, C.W.J. (1986). Developments in the study of cointegrated economic variables. Oxford Bulletin of Economics and Statistics 48: 213-28.

Gustafson, R. (1958). Carryover levels for grains. USDA. Technical bulletin 1178. Washington DC.

Hall, S.G., Robertson, D. and Wickens, M.R. (1997). Measuring economic convergence. International Jounal of Financial Economics 2:131-143.

Hanau, A. (1928). Die Prognose der Schweinepreise. Vierteljahreshefte zur Konjunkturforschung 7.

Ihle, R., Brümmer, B. and Thompson, S. R. (2012). Structural change in European calf markets: decoupling and the blue tongue disease. European Review of Agricultural Economics 39: 157-180.

Im K, Pesaran MH and Shin Y (2003). Testing for unit roots in heterogeneous panels. Journal of Economics 115:53-74. 
International Monetary Fund (IMF) (2012) World Economic Outlook Database. url: http://www.imf.org/external/pubs/ft/weo/2012/01/weodata/index.aspx [accessed: 27.08.2012].

Islam, N. (2003). What have we learnt from the convergence debate? Journal of Economic Surveys 17: 309- 362.

Johansen, S. (1988). Statistical Analysis of Cointegration Vectors. Journal of Economic Dynamics and Control 12: 231-254.

Kaabia, M. B. and Gil, J. M. (2000). Short- and long run effects of macroeconomic variables on the Spanish agricultural sector. European Review of Agricultural Economics 7: 449-471.

Kilian, S.; Antón, J.; Salhofer, K. and Röder, N. (2012). Impacts of 2003 CAP Reform on Land Rental Prices and Capitalization. Land Use Policy 29: 789-797.

Lapp, J.S. (1990). Relative Agricultural Prices and Monetary Policy. American Journal of Agricultural Economics 72:622-630.

Lastrapes, W.D. (2006). Inflation and the Distribution of Relative Prices: The Role of Productivity and Money Supply Shocks. Journal of Money, Credit and Banking 38:2159-2198.

Leon, J. and Soto, R. (1997). Structural breaks and long-run trends in commodity prices. Journal of International Development 9: 347-366.

Lucas, R.E.Jr. (1972). Expectations and Neutrality of Money. Journal of Economic Theory 4:103-124. 
Lucas, R. E. Jr. (1980) Two Illustrations of the Quantity Theory of Money. American Economic Review 70: 1005-14.

Mackowiak, B. and M. Wiederholt. 2009. “Optimal Sticky Prices under Rational Inattention.”American Economic Review 99:769-803.

Meyer, J. and Cramon-Taubadel, S. von (2004). Asymmetric Price Transmission: A Survey. Journal of Agricultural Economics 55: 581-611.

Nahar, S. and Inder, B. (1998). Testing convergence in economic growth for OECD countries. Monash University Working Paper 14/98.

Newbold, P., Rayner, T. and Kellard, N. (2000). Long-Run Drift, Co-Movement and Persistence in RealWheat and Maize Prices. Journal of Agricultural Economics 51:10621.

Newbold, P., Pfaffenzeller, S. and Rayner, A. (2005). How Well are Long-run Commodity Price Series Characterised by Trend Components? Journal of International Development 17: 479-494.

Newey, W. K. and West, K. D. (1987). A simple, positive semi-definite, heteroscedasticity and autocorrelation consistent covariance matrix. Econometrica 55: 703-708.

OECD (2005). The Impact on Yields of Arable Crops of Moving from Price Support to Area Payments - A study of the 1992 CAP Reform. Organisation for Economic Cooperation and Development. AGR/CA/APM(2004)17/Final. Paris: OECD.

Olekalns, N. (1996) Some Further Evidence on the Long-Run Neutrality of Money. Economics Letters 50: 393-98. 
Olivera, J. H. G. (1970) On Passive Money. Journal of Political Economy. Vol. 78:805814.

Orden, D. (1986). Agriculture, Trade, and Macroeconomics: The U.S. Case. Journal of Policy Modeling 8: 27-51.

Orden, D. (2010). Recent Macroeconomic Dynamics and Agriculture in Historical Perspective. Journal of Agricultural and Applied Economics 42:467-476.

Panopoulou, E. and Pantelidis, T. (2009). Club convergence in carbon dioxide emissions. Environmental and Resource Economics 44:47-70.

Pedroni, P. and Yao, J.Y. (2006). Regional income divergence in China. Journal of Asian Economics 17:294-315.

Pesaran, M. H. (2007). A pair-wise approach to testing for output and growth convergence. Journal of Econometrics 138:312-355.

Peterson, H.H., and Tomek, W.G. (2005). How Much of Commodity Price Behavior Can a Rational Expectations Storage Model Explain? Agricultural Economics 33:289_ 303.

Phillips, P.C.B., and S. Ouliaris (1990). Asymptotic properties of residual based tests for cointegration. Econometrica 58: 165-94.

Phillips, P. C. and Sul, D. (2007). Transition modeling and econometric convergence tests. Econometrica 75:1771-1855.

Phillips, P. C. and Sul, D. (2009). Economic transition and growth. Journal of applied Econometrics 24:1153-1185. 
Poghosyan, T. (2009). Are "new" and "old" EU members becoming more financially integrated? A threshold cointegration analysis. International Economics and Economic Policy 6: 259-281.

Proietti, T. (2005). Convergence in Italian regional per-capita GDP. Applied Economics 37:497-506.

Qayyum, A. 2006. "Money, Inflation and Growth in Pakistan.” The Pakistan Development Review 45: 203-212.

Quah, D. (1990). Permanent and Transitory Movements in Labor income: An explanation for 'Excess Smoothness' in consumption. Journal of Political Economy 98: 449- 475 .

Robertson, J.C. and Orden, D. (1990). Monetary Impacts on Prices in the Short and Long Run: Some Evidence from New Zealand. American Journal of Agricultural Economics 72: 160-171.

Saghaian, S.H., Reed, M.R. and Marchant, M.A. (2002). Monetary Impacts and Overshooting of Agricultural Prices in an Open Economy. American Journal of Agricultural Economics 84:90-103.

Sanjuan, A. I. and Gil, J. M. (2001). Price transmission analysis: a flexible methodological approach applied to European pork and lamb markets. Applied Economics 33:123-131.

Schuh, G. E. (1974). The exchange rate and U.S. agriculture. American Journal of Agricultural Economics 56: 1-13. 
Sckokai, P. and Moro, D. (2009). Modelling the impact of the CAP Single Farm Payment on farm investment and output. European Review of Agricultural Economics 36: $395-423$.

Seale, J.Jr., Regmi, A. and Bernstein, J. (2003). International Evidence on Food Consumption Patterns. Washington DC: U.S. Department of Agriculture, ERS Technical Bulletin No 1904, October.

Serletis, A. and Gogas, P. (2004). Long-horizon regression tests of the theory of purchasing power parity. Journal of Banking and Finance 28: 1961-1985.

Serletis, A. and Krause, D. P. (1996) Empirical Evidence on the Long-Run Neutrality Hypothesis Using Low-Frequency International Data. Economics Letters 50: 323-27.

Serra, T., Gil, J. M. and Goodwin, B. K. (2006). Local polynomial fitting and spatial price relationships: price transmission in EU pork markets European Review of Agricultural Economics 33: 415-436.

Serra, T., Stefanou, S., Gil, J. M. and Featherstone, A. (2009). Investment rigidity and policy measures. European Review of Agricultural Economics 36: 103-120.

Sims, C.A. (2003). Implications of Rational Inattention. Journal of Monetary Economics 50:665-690.

Solakoglu, E. G. and Civan, A. (2006). Agricultural price convergence across transition countries. Journal of Economic and Social Research 8:61-75.

St. Aubyn, M. (1999). Convergence across industrialized countries (1890-1989): New results using time series methods. Empirical Economics 24:23-44. 
Stigler, M. (2011). Commodity prices: theoretical and empirical properties. in Prakash, A. Safeguarding food security in volatile global markets. FAO. Rome.

Thiele, S. (2008). Food demand elasticities: an AIDS using German cross sectional date. Agrarwirtschaft 57: 258-268.

Toda, H. and T. Yamamoto (1995). Statistical Inference in Vector Autoregressions with Possibly Integrated Processes. Journal of Econometrics 66: 225 - 250.

Torero, M. and Braun, J. von (2008). Alternative mechanisms to reduce food price volatility and price spikes. Working paper. International Food Policy Research Institute (IFPRI). Washington DC: IFPRI.

Tweeten, L.G. (1980). An Econometric Investigation of Inflation Passthrough to the Farm Sector. Western Journal of Agricultural Economics 5: 89-106.

Wallace, F. H. (1999). Long-run neutrality of money in the Mexican economy. Applied Economics Letters 6: 637-639.

Wallace, F. H. and Shelley, G. L. (2006). An alternative test of purchasing power parity, Economics Letters 92: 177-183.

Wang, D. and Tomek, W. G. (2007). Commodity prices and unit root tests. American Journal of Agricultural Economics 89: 873-889.

Westerlund J. and M. Costantini, 2009. "Panel Cointegration and the Neutrality of Money." Empirical Economics, 36:1-26.

Williams, J. C. and Wright, B. D. (1991). Storage and Commodity Markets. Cambridge Books. Cambridge University Press. 
Young, A. T., Higgins, M. J. and Levy, D. (2007). Sigma convergence versus beta convergence: evidence from U.S. County-Level Data. Journal of Money, Credit and Banking 40: 1083-1093. 


\section{Curriculum Vitae}

Personal information:

Name Stefan Meyer

Address $\quad$ Weender Str. 96

37073 Göttingen

Date of Birth $\quad 23.11 .1982$

Place of Birth Nördlingen, Bayern, Deutschland

Education:

2003 - 2009 Diploma in Business Administration

Universität Regensburg

2009-2012 PhD in Agricultural Economics

Supervisor: Jun.-Prof. Xiaohua Yu, PhD

Courant Research Centre Poverty Equity and Growth

Georg-August-Universität Göttingen

Göttingen, den 13.09.2012 
